\title{
The Lindahl equilibrium in Schumpeterian growth models:
}

\author{
Knowledge diffusion, social value of innovations and optimal $R \& D$ \\ incentives*
}

Elie Gray ${ }^{\dagger}$, André Grimaud ${ }^{\ddagger}$

Working Paper - This draft: July 2015

Forthcoming in Journal of Evolutionary Economics

(DOI 10.1007/s00191-015-0417-5)

\begin{abstract}
The main motivation of the paper is to determine the social value of innovations in a standard scale-invariant Schumpeterian growth model, which explicitly introduces knowledge diffusion over a Salop (1979) circle. The social value of an innovation is defined as the optimal value of the knowledge inherent in this innovation. We thus have to price optimally knowledge. For that purpose, contrary to what is done in standard growth theory, we complete the markets using Lindahl prices for knowledge. The Lindahl equilibrium, which provides the system of prices that sustains the first-best social optimum in an economy with non rival goods, appears as a benchmark. First, its comparison with the standard Schumpeterian equilibrium à la Aghion \& Howitt (1992) enables us to shed a new light on the issue of non-optimality of the latter. Second, the Lindahl equilibrium also allows us to revisit the issue of R\&D incentives in presence of cumulative innovations. Finally, this benchmark may be a first step to understand how knowledge is exchanged in new technology sectors.
\end{abstract}

Keywords: growth theory - Lindahl equilibrium - Social value of innovations - Pareto suboptimality - Cumulative innovations - Knowledge spillovers

JEL Classification: D52 - O31 - O33 - O40 - O41

*We wish to thank Philippe Aghion, Jean-Luc Gaffard, Peter Howitt, Maurizio Iacopetta, Pietro Peretto, Gilles Saint-Paul, Bernard Salanié, John J. Seater, Francesco Vona, and the participants of the Workshop on Economic Growth (2011 and 2012) organized by NC State, OFCE and SKEMA Business School and of the EMAEE (2013) for their helpful comments and suggestions.

${ }^{\dagger}$ Corresponding author - Université de Toulouse, Toulouse Business School. 20 Bd. Lascrosses, BP 701031068 Toulouse Cedex 7, France. Tel.: +33 (0)5.61.29.49.25 . Email: e.gray@tbs-education.fr.

$\ddagger$ Université de Toulouse, Toulouse School of Economics (IDEI, LERNA) and Toulouse Business School. 20 Bd. Lascrosses, BP 701031068 Toulouse Cedex 7, France. Email: andre.grimaud@tse-fr.eu. 


\section{Introduction}

In this paper, we aim to define and to compute the social value of innovations in a standard endogenous growth model with vertical innovations that explicitly exhibits knowledge diffusion. For that purpose, in an Arrow-Debreu perspective, we use the concept of Lindahl equilibrium, which deeply departs from the type of equilibria generally considered in the literature.

The first requirement is to provide a precise definition of an innovation. Fundamentally, an innovation involves two types of goods: the new knowledge (a non rival good) inherent in this innovation and the intermediate good (a rival good) that embodies knowledge. Accordingly, we define an innovation as a pair "new knowledge / intermediate good". The standard literature on growth with vertical innovations generally focuses on a decentralized economy with creative destruction in line with the one introduced by Aghion \& Howitt (1992). In the whole paper, we name this type of equilibrium "Schumpeterian equilibrium à la Aghion \& Howitt". ${ }^{1}$ It considers incomplete markets since knowledge is not priced. Accordingly, $\mathrm{R} \& \mathrm{D}$ is indirectly funded by monopoly profits on intermediate goods that embody knowledge: intellectual property rights (IPRs), like patents, on these rival goods are introduced as a means to provide incentives to firms to invest in $\mathrm{R} \& \mathrm{D}$. Therefore, as usual in the literature, the value of innovations stems only from the stream of monopoly profits; that is why we call this value the private value of innovations.

We define the social value of an innovation as the optimal value of the knowledge inherent in the innovation. How should this value be computed? In order to answer this question, one has to determine the optimal price of knowledge. For that purpose, the relevant concept in our general equilibrium framework is the Lindahl equilibrium. Indeed, this equilibrium exhibits, by construction, the system of prices that sustains the first-best social optimum in presence of non rival goods. ${ }^{2}$ To the best of our knowledge, the Lindahl equilibrium has never been introduced in growth theory.

To construct the Lindahl equilibrium, we proceed as follows. First, all rival goods are priced at their marginal cost; this is in particular the case for intermediate goods (whereas, in standard Schumpeterian equilibria, there are monopolies on them). Second, we complete the markets; contrary to what is done in Schumpeterian equilibria, we price knowledge. Formally, at each date, each user of knowledge pays each unit of knowledge at a personalized price (the Lindahl price), and each innovator receives the sum of these Lindahl prices for each unit of knowledge inherent in his innovation.

How are these Lindahl prices computed in our endogenous growth model with knowledge diffusion? When an innovation occurs in a given intermediate sector, each unit of knowledge inherent in this innovation has an impact on three types of activities: the production of a final good, the production of the intermediate good of this sector, and the production of knowledge in all R\&D activities using this knowledge. For each of these three types of activities, we derive the Lindahl price of each unit of knowledge for each user (i.e. its willingness to pay for this unit): it is the marginal profitability of this unit for this user.

At this stage of the analysis, we have determined the system of prices sustaining the first-best social optimum. Thereupon, we have obtained the instantaneous optimal value of each unit of knowledge: it is the sum of the Lindahl prices. Since knowledge is infinitely-lived, the social value of each unit of knowledge is the discounted sum of these instantaneous optimal values. Finally, to obtain the social value of an innovation, we multiply the social value of each unit of knowledge by the number of units of knowledge inherent in this innovation. In line with ideas developed, for instance, in Tirole (1988), in Scotchmer (1991), or in Dasgupta, Mäler, Navaretti \& Siniscalco (1996), we thus determine, in a Schumpeterian growth framework, the overall income that each innovator should receive for his innovation in order to implement the first-best social optimum; it is the social value of his innovation.

Once we have defined and characterized the Lindahl equilibrium, we compare it with the standard Schumpeterian equilibrium. It occurs that the main differences between these two equilibria fundamentally stem from the market incompleteness in the Schumpeterian one. We know that, due to this incompleteness, $\mathrm{R} \& \mathrm{D}$ activities are not directly financed through the sale of the knowledge they produce when they innovate (as in the Lindahl equilibrium) but indirectly via the monopolies on intermediate goods embodying knowledge. This comparison helps us to understand better

\footnotetext{
${ }^{1}$ We consider Schumpeterian equilibria with unconstrained monopoly pricing only. In fact, we will exhibit a condition on the intensity of knowledge spillovers such that innovations are drastic. We thank an anonymous referee for remarks on this point.

${ }^{2}$ For further details and discussion, one can, for instance, refer to Milleron (1972) or to Mas-Colell, Whinston \& Green (1995 - Ch. 11 and Ch. 16).
} 
why, in the Schumpeterian equilibrium, the incentives may lead to too little or to too much R\&D investment. This equilibrium does not provide the optimal R\&D incentives for three basic reasons.

First, in the Schumpeterian equilibrium, the quantity of knowledge sold is not the optimal one. Indeed, in the Lindahl equilibrium, each innovator sells the incremental flow of knowledge inherent in his innovation. On the contrary, in the Schumpeterian equilibrium, when the latest innovator sells an intermediate good, he implicitly sells the whole stock of knowledge created in the sector so far, including all the knowledge created by each of his predecessors in this sector. This tends to provide too much $\mathrm{R} \& \mathrm{D}$ incentives to innovators.

Second, in the Schumpeterian equilibrium, this knowledge is not sold at the optimal price. Indeed, in the Lindahl equilibrium, all users of knowledge pay for it. On the contrary, in the Schumpeterian equilibrium, the knowledge created in a given sector is used freely to produce new knowledge by R\&D activities in other sectors, as well as in his sector (by subsequent innovators). This tends to provide too little R\&D incentives to innovators.

Third, in the Schumpeterian equilibrium, the period during which an innovation provides revenue to its producer is not the optimal one. In the Lindahl equilibrium, since knowledge is infinitely-lived, the innovator receives revenue forever. In the Schumpeterian equilibrium, because of the creative destruction mechanism, an innovator has a monopoly the lifespan of which is finite in average. This tends to provide too little R\&D incentives.

The sign of the overall effect - and thus whether the Schumpeterian equilibrium provides too little or too much R\&D incentives - depends on the intensity of knowledge spillovers, which itself depends on how much knowledge diffuses across sectors. The more knowledge diffuses, the more market incompleteness will be likely to lead to an insufficient allocation of resources in R\&D. This basically results from the second effect described above, because the revenue that an innovator should get from other R\&D activities increases with knowledge diffusion.

Not only does this comparison allow us to shed a new light on the issue of Pareto non-optimality of the Schumpeterian equilibrium, but it also allows us to revisit - within a dynamic general equilibrium model with accumulation and diffusion of knowledge - the issue of $R \& D$ funding raised by the presence of cumulative innovations. The main resulting issue consists in determining the payments that each innovator should receive in order to be given the optimal incentives. This has been tackled in many papers, both in the industrial organization literature (e.g. Scotchmer 1991; Green \& Scotchmer 1995; Bessen \& Maskin 2009) and in the growth literature (e.g. O'Donoghue \& Zweimüller 2004; Acemoglu \& Akcigit 2012; Chu, Cozzi \& Galli 2012). The typical focus is on profit division between sequential innovators, and on the design of IPRs that would provide appropriate R\&D incentives. Deriving the first-best prices system thanks to the Lindahl equilibrium enables us to establish the benchmark to compute exactly the revenue that each innovator should receive, as well as who should pay and how much. This is in line with ideas developed in Green \& Scotchmer (1995) who argue that "the social value of an early innovation includes the net social value of the applications it facilitates".

Finally, we think that the Lindahl equilibrium is a relevant concept to study the functioning of new technology sectors such as the software or biotechnology industries. Indeed, in these sectors, knowledge is embodied in intermediate goods that are akin to non rival goods (whereas they are rival in standard endogenous growth models). For instance, in the case of software, knowledge can be embodied in a CD-ROM, in a DVD, or even in other immaterial supports (e.g. via downloading), the marginal costs of production of which are almost nonexistent. One faces here a weightless economy in which non rival goods - that are named "knowledge-products" by Quah $(1997,2001)$ or "information goods" by Scotchmer (2005) - do have a price. In fact, because some of these knowledge goods can be directly protected by IPRs (e.g. softwares, databases, business plans, molecules, ...), their price is positive, even though the marginal cost is zero. Even though these issues remain out of the scope of this paper, one can think that the Lindahl equilibrium gives the benchmark to introduce these new sectors in the analysis. Indeed, since it enables us to price knowledge, it is a first step to formalize the coordination on this type of good.

The paper is organized as follows. In Section 2, we present a scale-invariant fully endogenous growth model with vertical innovations which explicitly formalizes knowledge diffusion, and we provide the first-best social optimum. In Section 3, we analyze two equilibria: the Schumpeterian equilibrium and the Lindahl equilibrium. We conclude in Section 4. All computations are provided in the Appendix, Section 5. 


\section{Model and welfare}

In this section, we present a continuous-time scale-invariant fully endogenous Schumpeterian growth model, in which knowledge can diffuse, with more or less intensity, across the sectors' R\&D activity. First, we present the technologies and the preferences, which are independent of the two concepts of equilibria that will be studied in Section 3 below. Then, we characterize the first-best social optimum.

\subsection{Technologies and preferences}

We begin this subsection by presenting a general law of knowledge accumulation. Then, we introduce explicitly inter-sectoral knowledge diffusion by exploiting the circular product differentiation model of Salop (1979). Finally, we plug this technology of knowledge creation in a standard endogenous growth model with vertical innovations in line with Grossman \& Helpman (1991) and Aghion \& Howitt (1992). ${ }^{3}$

There is a continuum $\Omega$, of measure $N$, of intermediate sectors uniformly distributed on a clockwise oriented circle. At each date $t$, each sector $\omega, \omega \in \Omega$, is characterized by a stock of knowledge $\chi_{\omega t}$ and by an intermediate good $\omega$, produced in quantity $x_{\omega t}$, which embodies this stock of knowledge. As usual in endogenous growth theory, we assume that all sectors have an identical initial level of knowledge, i.e. $\chi_{\omega 0}=\chi_{0}, \forall \omega \in \Omega{ }^{4}$ Assuming that knowledge is homogenous, the whole stock of knowledge disposable in the economy at each date $t$ is

$$
\mathcal{K}_{t}=\int_{\Omega} \chi_{\omega t} d \omega
$$

The initial stock $\mathcal{K}_{0}$ is normalized to one.

Each sector has its own R\&D activity which is dedicated to the creation of innovations. In the remaining of the paper, an innovation is defined as follows:

Definition 1. An innovation at date $t$ in any sector $\omega, \omega \in \Omega$, consists in i) an increase of $\Delta \chi_{\omega t}$ units of new knowledge in this sector, and ii) the embodiment of this new knowledge in the intermediate good $\omega$.

This definition - in which we carefully distinguish between the intermediate good embodying knowledge and knowledge itself - will turn out to be crucial in Section 3 when we determine the values of innovations.

\subsubsection{Knowledge accumulation}

It is commonly agreed that new knowledge is produced using two types of inputs: rival goods (e.g. labor, physical capital, final good), and a non rival one (a stock of knowledge previously created). In the present model, as in standard Schumpeterian growth theory, the mechanism at the source of the creation of knowledge relies on two core assumptions. First, the innovation process is uncertain:

Assumption 1. If $l_{\omega t}$ is the amount of labor devoted to R\&D at date $t$ in any intermediate sector $\omega, \omega \in \Omega$, to move on to the next quality of intermediate good $\omega$, innovations occur randomly with a Poisson arrival rate $\lambda l_{\omega t}, \lambda>0$.

Second, each R\&D activity creates new knowledge making use of previously created knowledge. This idea is formalized by considering that, in order to produce new knowledge, in each sector $\omega$, R\&D activity draws from a specific pool of knowledge $\mathcal{P}_{\omega t}$. Formally, we assume that, for any intermediate good $\omega, \omega \in \Omega$, if an innovation occurs at date $t$, the increase in knowledge $\Delta \chi_{\omega t}$ (i.e. the quality improvement of the intermediate good) depends positively on the current size of the pool of knowledge from which this sector's R\&D activity draws. In order to simplify computations, this relation is assumed to be linear:

Assumption 2. For any intermediate sector $\omega, \omega \in \Omega$, if an innovation occurs at date $t$, the increase in knowledge is $\Delta \chi_{\omega t}=\sigma \mathcal{P}_{\omega t}, \sigma>0$.

\footnotetext{
${ }^{3}$ Since we will make assumptions to obtain a scale-invariant fully endogenous growth model, the technologies considered here are in fact closer to Aghion \& Howitt (1998 - Ch. 12), to Howitt (1999), or to Aghion \& Howitt (2009 - Ch. 4).

${ }^{4}$ We provide more details on this assumption of symmetry across sectors (which is standard in endogenous growth theory) below at the end of Subsection 2.1.3.
} 
From Assumptions 1 and 2, one derives the law of motion of the average knowledge inherent in any sector $\omega$ :

Lemma 1. Under Assumptions 1 and 2, the expected knowledge in any intermediate sector $\omega, \omega \in$ $\Omega$, is a differentiable function of time. The law of knowledge accumulation is $\dot{\chi}_{\omega t}=\lambda \sigma l_{\omega t} \mathcal{P}_{\omega t}, \forall \omega \in$ $\Omega .^{5}$

Proof. See Appendix 5.1.1.

As underlined for instance by Aghion \& Howitt (1998), Howitt (1999), Jones (1999), Laincz \& Peretto (2006), and Dinopoulos \& Sener (2007), most growth models differ mainly in the specification of the knowledge production technology. ${ }^{6}$ The law of knowledge accumulation derived in Lemma 1 encompasses several of the ones assumed in the standard fully endogenous growth theory. Indeed, depending on the specification of the pools of knowledge $\mathcal{P}_{\omega t}$, a large number of growth models can be obtained using the present formalization. In Appendix 5.1.2, we provide several illustrations: models without knowledge spillovers, models considering only intra-sectoral knowledge spillovers, models assuming knowledge spillovers that depend on average knowledge, models in which spillovers depend on the knowledge level of the frontier firms ("leading-edge technology") and models with global knowledge spillovers (i.e. knowledge diffuses to the whole economy).

\subsubsection{Knowledge diffusion and pools of knowledge}

In Lemma 1, it appears that the new knowledge created in each sector $\omega$ depends on the pool of knowledge $\mathcal{P}_{\omega t}$ used by the R\&D activity in this sector. Now, we propose a mechanism formalizing how these pools are shaped. As a matter of fact, the constitution of each of these pools relies on the influence that R\&D activities have on each other. The significance of the interactions between sectors has universally been underlined. In particular, several empirical studies stress that R\&D performed in one sector may produce positive spillovers effects in other sectors (see, for instance, Griliches 1992; Griliches 1995; or Hall, Mairesse \& Mohnen 2010). As stated by Hall et al., "such spillovers are all the more likely and significant as the sender and the receiver are closely related". Moreover, as argued in Hall (2004), "it is safe to say that without diffusion, innovation would have little social or economic impact. In the study of innovation, the word diffusion is commonly used to describe the process by which individuals and firms in a society/economy adopt a new technology, or replace an older technology with a newer". In direct line with these statements, we explicitly introduce a process of knowledge diffusion. ${ }^{7}$ Formally, each sector $\omega, \omega \in \Omega$, is simultaneously a sender and a receiver of knowledge. Let us denote by $\mathcal{D}_{\omega}$ the subset of sectors of $\Omega$ that use the knowledge $\chi_{\omega t}$ produced by R\&D activity $\omega$, and by $\Omega_{\omega}$ the subset of sectors of $\Omega$ that contribute to the pool of knowledge $\mathcal{P}_{\omega t}$ used by R\&D activity $\omega$.

In order to provide an explicit expression of this pool of knowledge, we introduce the concept of scope of diffusion of knowledge $\chi_{\omega t}$. This scope of diffusion is defined as the measure of $\mathcal{D}_{\omega}$. To avoid too much complexity, we make the following set of assumptions:

Assumption 3. The scope of diffusion of knowledge is identical for all sectors $\omega, \omega \in \Omega$. We denote it by the parameter $\theta$, where $1<\theta \leq N$. Moreover, for any intermediate sector $\omega, \omega \in \Omega$, when an innovation occurs, knowledge diffuses symmetrically over the circle $\Omega$.

Assumption 3 has the following consequences. First, regarding the diffusion of knowledge, the subset of sectors of $\Omega$ that use the knowledge $\chi_{\omega t}$ produced by R\&D activity $\omega$ is $\mathcal{D}_{\omega}=$

\footnotetext{
${ }^{5}$ The expectation operator is dropped to simplify notations: $\frac{\partial \mathbb{E}\left[\chi_{\omega t}\right]}{\partial t} \equiv \dot{\chi}_{\omega t}$.

${ }^{6}$ The overviews provided by these authors propose a classification of the various growth models according to their key result with respect to the presence of scale effects. Three classes of models emerge: endogenous growth models exhibiting this non desirable property (e.g. the models of Romer 1990, Grossman \& Helpman 1991, or Aghion \& Howitt 1992), semi-endogenous growth models introducing decreasing returns to scale to suppress scale effect (e.g. the models of Jones 1995, Kortum 1997, or Segerstrom 1998), and fully endogenous growth models, which eliminate scale effects by allowing for expansion in the number of sectors (e.g. the models of Aghion \& Howitt 1998 - Ch. 12, Dinopoulos \& Thompson 1998 Peretto 1998, Young 1998, Howitt 1999, Peretto 1999, or Aghion \& Howitt 2009 Ch. 4).

${ }^{7}$ The term "diffusion" has often been used to refer to the phenomenon involving that, as stated by Chari \& Hopenhayn (1991), "there is a lag between the appearance of a technology and its peak usage". The fact that a lag can be involved by technology adoption remains to be explored within our model and is left for further research. One could, for instance, consider that the more distant two sectors are, the longer the lag in technology adoption. This temporal dimension of knowledge diffusion is undoubtedly important. However, in this paper, we abstract away from it by considering instantaneous diffusion, and we focus on "spatial diffusion".
} 
$[\omega-\theta / 2 ; \omega+\theta / 2]$. Second, regarding the reception of knowledge, the set of sectors that contribute to the pool of knowledge used by $\mathrm{R} \& \mathrm{D}$ activity $\omega$ is $\Omega_{\omega}=[\omega-\theta / 2 ; \omega+\theta / 2]$. Clearly, under Assumption 3 , one has $\mathcal{D}_{\omega}=\Omega_{\omega} \cdot{ }^{8}$ Consequently, one gets the following simple expression of the pools of knowledge:

Lemma 2. At each date $t$, in any intermediate sector $\omega$, the pool of knowledge used by the RED activity is $\mathcal{P}_{\omega t}=\int_{\Omega_{\omega}} \chi_{h t} d h, \forall \omega \in \Omega$.

Gathering Lemmas 1 and 2, one obtains:

Proposition 1. At each date $t$, in any intermediate sector $\omega$, knowledge is produced along with

$$
\dot{\chi}_{\omega t}=\lambda \sigma l_{\omega t} \mathcal{P}_{\omega t}, \text { where } \mathcal{P}_{\omega t}=\int_{\Omega_{\omega}} \chi_{h t} d h, \forall \omega \in \Omega
$$

Proposition 1 underlines the fact that the R\&D activity of a given sector always uses the knowledge accumulated so far in this sector and potentially captures part of the mass of the ideas created in all others. This subset of $\mathcal{K}_{t}$ is more or less large. This depends on the scope of knowledge diffusion $\theta$. This formalization generalizes the standard innovation-based endogenous growth theory. Indeed, depending on the choice of the parameter $\theta$, one obtains a large collection of pools, $\mathcal{P}_{\omega t}$, and thus of models. ${ }^{9}$

\subsubsection{Other assumptions}

The remaining assumptions are standard in Schumpeterian growth theory. Intertemporal preferences of the representative household are given by

$$
\mathcal{U}=\int_{0}^{\infty} u\left(c_{t}\right) e^{-\rho t} d t
$$

where $\rho$ is the subjective discount rate and $u\left(c_{t}\right)$ is the individual instantaneous utility at date $t$, which is given by $u\left(c_{t}\right)=\ln \left(c_{t}\right) \cdot{ }^{10}$ At each date $t$, each of the $L$ identical households is endowed with one unit of labor that is supplied inelastically. ${ }^{11}$ In order to remove the non-desirable scale effects property, we use the commonly shared assumption of proportionality between the size of the population and the number of sectors: $N=\gamma L$, where $\gamma$ is a strictly positive parameter. ${ }^{12}$ The total quantity of labor, $L$, is used to produce the final good and in R\&D activities. Thus, the labor constraint is

$$
L_{t}=L_{t}^{Y}+\int_{\Omega} l_{\omega t} d \omega
$$

Besides labor, the production of the final good requires the use of all available intermediate goods, each of which is associated with its own level of knowledge. The final good production technology is

$$
Y_{t}=\left(L_{t}^{Y}\right)^{1-\alpha} \int_{\Omega} \chi_{\omega t}\left(x_{\omega t}\right)^{\alpha} d \omega, 0<\alpha<1
$$

The final good has two competing uses. First, it is consumed by the representative household in quantity $c_{t}$. Second, it is used in the production of intermediate goods along with

$$
x_{\omega t}=\frac{y_{\omega t}}{\chi_{\omega t}}, \omega \in \Omega,
$$

\footnotetext{
${ }^{8}$ More generally, if each sector $\omega$ had its own scope of knowledge diffusion $\theta_{\omega}$, then one would have $\mathcal{D}_{\omega}=$ $\left\{h \in \Omega /|\omega-h| \leq \frac{\theta_{\omega}}{2}\right\}$ and $\Omega_{\omega}=\left\{h \in \Omega /|\omega-h| \leq \frac{\theta_{h}}{2}\right\}$.

${ }^{9}$ For instance, if the parameter $\theta$ is assumed to be equal to $N$, there is global inter-sectoral diffusion: $\mathcal{D}_{\omega}=\Omega_{\omega}=$ $\Omega, \forall \omega \in \Omega$. Thus, all sectors use the whole stock of knowledge in the economy: $\mathcal{P}_{\omega t}=\int_{\Omega} \chi_{h t} d h=\mathcal{K}_{t}, \forall \omega \in \Omega$ (see Lemma 2 and equation (1)). Finally, the law of knowledge accumulation in each sector $\omega$ is $\dot{\chi}_{\omega t}=\lambda \sigma l_{\omega t} \mathcal{K}_{t}, \forall \omega \in$ $\Omega$. In this case, the expression of the law of knowledge accumulation, which is here endogenously derived from assumptions made in a stochastic quality ladders model, leads to a law of motion of the whole disposable knowledge that is formally identical to the knowledge production function initially introduced by Romer (1990). Indeed, differentiating (1) with respect to time yields $\dot{\mathcal{K}}_{t}=\int_{\Omega} \dot{\chi}_{\omega t} d \omega=\lambda \sigma\left(\int_{\Omega} l_{\omega t} d \omega\right) \mathcal{K}_{t} \Leftrightarrow \dot{\mathcal{K}}_{t}=\lambda \sigma L_{t}^{R} \mathcal{K}_{t}$, where $L_{t}^{R}=$ $\int_{\Omega} l_{\omega t} d \omega$ is the total amount of labor used in R\&D.

${ }_{10}$ The results are robust if one considers a more general C.E.S. instantaneous utility function of parameter $\varepsilon$, $u\left(c_{t}\right)=c_{t}^{1-\varepsilon} /(1-\varepsilon)$.

${ }^{11}$ The results are robust if one considers constant population growth.

${ }^{12}$ This assumption - which is a necessary condition to cancel scale effects in fully endogenous growth model - has been justified both theoretically and empirically. See, for instance, Aghion \& Howitt (1998 - Ch. 12), Jones (1999), Segerstrom (2000), Laincz \& Peretto (2006), or Dinopoulos \& Sener (2007). Besides, it is not needed for obtaining the main insight of this paper and is introduced only in order to consider a scale-invariant fully endogenous growth model.
} 
where $y_{\omega t}$ is the quantity of final good used to produce $x_{\omega t}$ units of intermediate good $\omega$. This usual technology illustrates the increasing complexity in the production of intermediate goods: as the quality of intermediate good $\omega$ (measured by the stock of knowledge $\chi_{\omega t}$ ) increases, the production of this intermediate good requires more final good. In other words, the larger the stock of knowledge in the sector, the more costly the production of the intermediate good embodying it. One gets the following constraint on the final good market:

$$
Y_{t}=L c_{t}+\int_{\Omega} y_{\omega t} d \omega
$$

As usual in growth models, we will consider the assumption of symmetry across sectors. ${ }^{13}$ This assumption relates to the labor devoted to each R\&D activity and to the stock of knowledge in each sector. Formally it will be assumed that $l_{\omega t}=l_{t}$ and $\chi_{\omega t}=\chi_{t}, \forall \omega \in \Omega$, when computing the first-best optimum, the Schumpeterian equilibrium and the Lindahl equilibrium (this appears clearly in the corresponding appendices). By way of example, let us rewrite (1) and (2) under symmetry. The whole stock of knowledge in the economy is now $\mathcal{K}_{t}=\int_{\Omega} \chi_{\omega t} d \omega=N \chi_{t}$. Besides, the pools of knowledge become $\mathcal{P}_{\omega t}=\mathcal{P}_{t}=\theta \chi_{t}, \forall \omega \in \Omega$; and the resulting law of motion of knowledge is $\dot{\chi}_{\omega t}=\dot{\chi}_{t}=\lambda \sigma \theta l_{t} \chi_{t}, \forall \omega \in \Omega$.

\section{$2.2 \quad$ First-best social optimum}

The first-best social optimum is the solution of the maximization of the representative household's discounted utility (3) subject to (1), (2), (4), (5), (6) and (7). Proposition 2 gives the complete characterization of the optimum. From now on, we denote by $g_{z_{t}}$ the rate of growth, $\dot{z}_{t} / z_{t}$, of any variable $z_{t}$, and we use the superscript "o" for "social optimum".

Proposition 2. In the first-best social optimum, the partition of labor, the quantity of each intermediate good $\omega$, and the growth rates are respectively

$$
\begin{gathered}
L_{t}^{Y o}=L^{Y o}=\frac{\rho \gamma L}{\lambda \sigma \theta}, l_{\omega t}^{o}=l^{o}=\frac{1}{\gamma}-\frac{\rho}{\lambda \sigma \theta}, x_{\omega t}^{o}=x^{o}=\alpha^{\frac{1}{1-\alpha}} \frac{\rho \gamma L}{\lambda \sigma \theta}, \\
\text { and } g_{c_{t}}^{o}=g_{Y_{t}}^{o}=g_{\mathcal{K}_{t}}^{o}=g_{\chi_{\omega t}}^{o}=g^{o}=\frac{\lambda \sigma \theta}{\gamma}-\rho, \forall \omega \in \Omega, \forall t
\end{gathered}
$$

Proof. See Appendix 5.2.

The three parameters $\lambda, \sigma$ and $\theta$ all account for the productivity of R\&D activities. At the first-best, an increase in any of them leads to a reallocation of labor from the production to R\&D activity, and thus to a higher growth rate. The parameter $\lambda$ stands for the productivity of the labor devoted to the creation of innovations (see Assumption 1). The parameter $\sigma$ stands for the productivity of knowledge used by a given sector in the creation of new knowledge: it indicates to what extent the pools of knowledge contribute to the increases in knowledge when innovations occur. As seen in Assumption 2, $\sigma$ is a measure of the contribution of the pool to the height of the jump in knowledge $\Delta \chi_{\omega t}=\sigma \mathcal{P}_{\omega t}$. The parameter $\theta$ (the scope of knowledge diffusion) is another measure of the efficiency of knowledge: as seen in Assumption 3 and in Lemma 2, it stands for the overall influence of any innovation in the constitution of the pools of knowledge. To sum up, when knowledge is created, $\theta$ relates to the mass of sectors receiving this knowledge, whereas $\sigma$ relates to the impact of this knowledge on the production of new knowledge created by these receivers. In this model, these two parameters often appear in the form of the product $\sigma \theta$, which we refer to as the intensity of knowledge spillovers.

To conclude this section, let us underline that, in the technologies presented above in Subsection 2.1 , each unit of knowledge $\chi_{\omega t}$ involved by any innovation produced in a given sector $\omega$ affects simultaneously the final good sector (see (5)), the intermediate good sector $\omega$ (see (6)), and a more or less significant range of $R \& D$ activities (see (2)): the presence of knowledge involves a public (i.e. non rival) good issue. In the standard literature, this issue is commonly referred

\footnotetext{
${ }^{13}$ The assumption of symmetry across sectors is standard in endogenous growth theory; see, for instance, Aghion \& Howitt (1992 or 1998 - Ch. 3), or Peretto \& Smulders (2002). For more details on this issue, the reader can refer to Peretto $(1998,1999)$ or to Cozzi, Giordani \& Zamparelli (2007) in which the relevancy of the symmetric equilibrium is discussed.
} 
to as "knowledge spillovers" and relates both to knowledge diffusion and to an implicit market incompleteness (in the decentralized economies generally studied, knowledge is not priced; see, for instance, the equilibria studied in Romer 1990 and in Aghion \& Howitt 1992). The knowledge spillovers issue has extensively been tackled in the literature (e.g. Aghion \& Howitt 1992, 1998, 2009; Li 2002; Peretto \& Smulders 2002; Jones 2005; Acemoglu 2009). We think that introducing Lindahl prices - and thus the Lindahl equilibrium - in the analysis allows us to clarify this issue.

\section{$3 \quad$ Schumpeterian equilibrium à la Aghion \& Howitt, Lindahl equilibrium, and values of innovations}

In the previous section, we have seen that innovations involve both new units of knowledge (i.e. non rival goods) and intermediate goods (i.e. rival goods) in which this knowledge is embodied. In all what follows, it is fundamental to distinguish between the two.

In order to deal with the non-rivalry property of knowledge, the seminal papers by Romer (1990), Grossman \& Helpman (1991), and Aghion \& Howitt (1992), focused on a decentralized equilibrium with incomplete markets and imperfect competition. Indeed, in this type of equilibria, a market and a price are specified for intermediate goods that incorporate knowledge, but not for knowledge itself; positive monopoly profits on the sale of intermediate goods, which result from intellectual property rights granted to innovators, are used as incentives to invest in the creation of knowledge. This framework, which has become the standard in the endogenous growth literature, provides a realistic decentralized economy in which $R \& D$ activity is privately and indirectly funded: the value of innovations stems from the stream of monopoly profits on the sale of intermediate goods embodying knowledge.

The main motivation of our study is to address the following question: what is the social value of innovations in a dynamic general equilibrium model in which knowledge accumulation plays a key part? To answer this question, we first define the social value of an innovation in any sector $\omega$ as the optimal value of the knowledge inherent in this innovation, $\Delta \chi_{\omega t}$. How shall it then be computed? For that purpose, contrary to what is done in the standard literature, we price knowledge, that is, we complete the markets. Thus, we use the concept of Lindahl equilibrium which provides the system of prices that sustains the first-best optimum in an economy with non rival goods.

In this section, we study two types of equilibria. For each of them, we formally define and compute the equilibrium and the resulting value of innovations. In Subsection 3.1, we consider the standard Schumpeterian equilibrium à la Aghion \& Howitt (1992) and, as commonly done in the related literature, we derive the private value of innovations that results from the sale of intermediate goods. ${ }^{14}$ In Subsection 3.2, we consider the Lindahl equilibrium and we derive the social value of these innovations, which is obtained by introducing the concept of Lindahl prices in endogenous growth theory. ${ }^{15}$ Then, in Subsection 3.3, we underline the main differences between these two equilibria.

We normalize the price of final good to one, and we denote respectively by $w_{t}, r_{t}$ and $q_{\omega t}$ $(\omega \in \Omega)$ the wage, the interest rate and the price of intermediate good $\omega$ at date $t$.

\subsection{Schumpeterian equilibrium and private value of innovations}

\subsubsection{Definition and characterization of the Schumpeterian equilibrium}

Here, we recall the main features of the standard Schumpeterian equilibrium à la Aghion \& Howitt (1992), which involves a fundamental externality (knowledge is not priced). In order to fund indirectly knowledge creation, one generally considers the following assumptions inspired by Schumpeter's creative destruction mechanism. Once an innovation occurs, the resulting knowledge is embodied in an intermediate good; then, the innovator is granted an infinitely-lived patent and monopolizes the production and sale of this private good until replaced by the next innovator. In such a decentralized economy, Pareto non-optimality may arise (the equilibrium allocation of labor in R\&D can either be sub-optimal or over-optimal). This follows from two market failures. The first one results from the presence of monopolies on intermediate goods; it can be corrected by an

\footnotetext{
${ }^{14}$ Alternatively, we could refer to the private value of an innovation as its Schumpeterian value, its rival value, or its patent value.

${ }^{15}$ Alternatively, we could call the social value of an innovation, its Lindahl value, its non rival value, or its optimal value.
} 
ad valorem subsidy $\psi$ on each intermediate good demand. The second one relates to the externality triggered by the fact that there is no market for knowledge; it can be corrected by a public tool $\varphi$ which, as explained below, can consist in a subsidy or in a tax on the profits of R\&D activities. Before implementing the first-best social optimum, we construct the set of Schumpeterian equilibria as follows:

Definition 2. At each vector of public policy tools $(\psi, \varphi)$ is associated a particular Schumpeterian equilibrium à la Aghion 8 Howitt. It consists of time paths of set of prices

$$
\left\{\left(w_{t}(\psi, \varphi), r_{t}(\psi, \varphi),\left\{q_{\omega t}(\psi, \varphi)\right\}_{\omega \in \Omega}\right)\right\}_{t=0}^{\infty}
$$

and of quantities

$$
\left\{\left(c_{t}(\psi, \varphi), Y_{t}(\psi, \varphi),\left\{x_{\omega t}(\psi, \varphi)\right\}_{\omega \in \Omega}, L_{t}^{Y}(\psi, \varphi),\left\{l_{\omega t}(\psi, \varphi)\right\}_{\omega \in \Omega},\left\{\chi_{\omega t}(\psi, \varphi)\right\}_{\omega \in \Omega}\right)\right\}_{t=0}^{\infty}
$$

such that: the representative household maximizes his utility; firms maximize their profits; the final good market, the financial market and the labor market are perfectly competitive and clear; on each intermediate good market, the innovator is granted an infinitely-lived patent and monopolizes the production and sale until replaced by the next innovator; and there is free entry on each RED activity (i.e. the zero profit condition holds for each RED activity).

Henceforth, we consider the case of Schumpeterian equilibria with unconstrained monopoly pricing, that is, with drastic innovations. In our framework, this occurs if and only if $\sigma \theta>$ $1 / \alpha^{\frac{\alpha}{1-\alpha}}-1$ (see (57) in Appendix 5.3), that is, if and only if the intensity of knowledge spillovers is sufficiently high. The proof is given in the remark at the end of Appendix 5.3. This condition generalizes the one obtained in Aghion \& Howitt (1992): see their condition (5.3), page 340. What is new in our framework with respect to theirs is the presence of the parameter $\theta$, the scope of knowledge diffusion, in the condition characterizing drastic innovations. The basic mechanism explaining this result is the following. The larger $\theta$, the larger the pools of knowledge, since $\mathcal{P}_{\omega t}=\int_{\Omega_{\omega}} \chi_{h t} d h$ where $\Omega_{\omega}=[\omega-\theta / 2 ; \omega+\theta / 2]$. Thus, the larger $\theta$, the larger the increase in knowledge when innovations occur, since $\Delta \chi_{\omega t}=\sigma \mathcal{P}_{\omega t}$ from Assumption 2. Finally, the larger $\theta$ is, the more likely innovations are drastic.

The agents' behaviors are detailed in Appendix 5.3 and the set of equilibria is characterized in Proposition 3 below.

Proposition 3. At each date $t$, the set of Schumpeterian equilibria à la Aghion E Howitt is characterized as follows.

- The quantities and the growth rates are $L_{t}^{Y}(\psi, \varphi)=L^{Y}(\psi, \varphi)=\frac{\gamma L\left(\frac{\lambda}{\gamma}+\rho\right)}{\lambda\left(1+\frac{1+\varphi}{1-\psi} \alpha\right)} ; l_{\omega t}(\psi, \varphi)=$

$$
\begin{aligned}
& l(\psi, \varphi)=\frac{1}{\gamma}-\frac{L^{Y}(\psi, \varphi)}{\gamma L}, \forall \omega \in \Omega ; \\
& x_{\omega t}(\psi, \varphi)=x(\psi, \varphi)=\left(\frac{\alpha^{2}}{1-\psi}\right)^{\frac{1}{1-\alpha}} L^{Y}(\psi, \varphi), \forall \omega \in \Omega ; \\
& g_{c_{t}}=g_{Y_{t}}=g_{\mathcal{K}_{t}}=g_{\chi_{\omega t}}=g(\psi, \varphi), \forall \omega \in \Omega, \\
& \text { where } g(\psi, \varphi)=\lambda \sigma \theta l(\psi, \varphi)=\lambda \sigma \theta\left[\frac{1}{\gamma}-\frac{\frac{\lambda}{\gamma}+\rho}{\lambda\left(1+\frac{1+\varphi}{1-\psi} \alpha\right)}\right] .
\end{aligned}
$$

- The prices are $w_{t}(\psi, \varphi)=(1-\alpha)\left(\frac{\alpha^{2}}{1-\psi}\right)^{\frac{\alpha}{1-\alpha}} \mathcal{K}_{t}(\psi, \varphi) ; r(\psi, \varphi)=g(\psi, \varphi)+\rho q_{\omega t}(\psi, \varphi)=$ $q_{t}(\psi, \varphi)=\frac{\mathcal{K}_{t}(\psi, \varphi)}{\alpha \gamma L}, \forall \omega \in \Omega$, in which $\mathcal{K}_{t}(\psi, \varphi)=e^{g(\psi, \varphi) t}$

Proof. See Appendix 5.3.

The first-best social optimum can be implemented within this Schumpeterian equilibrium: the optimal set of public tools $\left(\psi^{o}, \varphi^{o}\right)$ can be obtained by identifying the equilibrium growth rate and quantities of intermediate goods, $g(\psi, \varphi)$ and $x(\psi, \varphi)$, with the optimal ones, $g^{o}$ and $x^{o}{ }^{16}$ One gets the following corollary to Proposition 3.

\footnotetext{
${ }^{16}$ One gets:

$$
\left\{\begin{array} { l } 
{ g ( \psi ^ { o } , \varphi ^ { o } ) = g ^ { o } } \\
{ x ( \psi ^ { o } , \varphi ^ { o } ) = x ^ { o } }
\end{array} \Leftrightarrow \left\{\begin{array} { l } 
{ L ^ { Y } ( \psi ^ { o } , \varphi ^ { o } ) = \frac { \rho \gamma L } { \lambda \sigma \theta } } \\
{ ( \frac { \alpha ^ { 2 } } { 1 - \psi ^ { o } } ) ^ { \frac { 1 } { 1 - \alpha } } L ^ { Y } ( \psi ^ { o } , \varphi ^ { o } ) = \alpha ^ { \frac { 1 } { 1 - \alpha } } \frac { \rho \gamma L } { \lambda \sigma \theta } }
\end{array} \Leftrightarrow \left\{\begin{array}{l}
\varphi^{o}=\sigma \theta\left(\frac{\lambda}{\gamma \rho}+1\right)-2 \\
\psi^{o}=1-\alpha
\end{array}\right.\right.\right.
$$
}


Corollary. The optimal tools are $\psi^{o}=1-\alpha$, and $\varphi^{o}=\frac{\sigma \theta}{\rho}\left(\frac{\lambda}{\gamma}+\rho\right)-2$.

The optimal tool used to correct the monopoly distortion is the usual subsidy $\left(\psi^{o}>0\right)$ on each intermediate good demand; as mentioned above, the optimal tool correcting the externality entailed by market incompleteness can consist either in a subsidy $\left(\varphi^{o}>0\right)$ or in a $\operatorname{tax}\left(\varphi^{o}<0\right)$ on monopoly profits. Note that we recover here the standard result along with $\varphi^{\circ}$ is an increasing function of the intensity of knowledge spillovers $\sigma \theta$. On this issue, see, for instance, $\operatorname{Li}(2003)$. We return to this result below in Subsection 3.3.

\subsubsection{Private value of innovations}

In the Schumpeterian equilibrium à la Aghion \& Howitt (1992), in any sector $\omega, \omega \in \Omega$, the incumbent innovator having successfully innovated at date $t$ receives, at any date $\tau>t$, the net profit $\pi_{\tau}^{x_{\omega}}(\psi, \varphi)$ with probability $e^{-\int_{t}^{\tau} \lambda l_{\omega u}(\psi, \varphi) d u}(i . e$. provided that there is no innovation upgrading intermediate good $\omega$ between $t$ and $\tau$ ). Given the governmental intervention on behalf of $\mathrm{R} \& \mathrm{D}$ activities and the intermediate good production function (6), this profit is

$$
\begin{aligned}
\pi_{\tau}^{x_{\omega}}(\psi, \varphi)=(1+\varphi)\left[q_{\omega \tau}(\psi, \varphi) x_{\omega \tau}(\psi, \varphi)-y_{\omega \tau}(\psi, \varphi)\right] \\
=(1+\varphi)\left[q_{\omega \tau}(\psi, \varphi)-\chi_{\omega \tau}(\psi, \varphi)\right] x_{\omega \tau}(\psi, \varphi)
\end{aligned}
$$

As usual, we define the private value of the latest innovation in sector $\omega$ as the sum of the present values of the incumbent's expected net profits on the sale of intermediate good $\omega$ :

Definition 3. Consider an innovation at date $t$ in any sector $\omega, \omega \in \Omega$. Its private value is

$$
\Pi_{\omega t}^{x}(\psi, \varphi)=\int_{t}^{\infty} \pi_{\tau}^{x_{\omega}}(\psi, \varphi) e^{-\int_{t}^{\tau}\left[r_{u}(\psi, \varphi)+\lambda l_{\omega u}(\psi, \varphi)\right] d u} d \tau
$$

$$
\text { where } \pi_{\tau}^{x_{\omega}}(\psi, \varphi) \text { is given by }(8)
$$

The computation of this value is provided in Appendix 5.3; see equation (43). One gets the following proposition:

Proposition 4. The private value of an innovation at date $t$ in any sector $\omega, \omega \in \Omega$, is

$$
\Pi_{\omega t}^{x}(\psi, \varphi)=\Pi_{t}^{x}(\psi, \varphi)=\frac{1-\alpha}{\lambda}\left(\frac{\alpha^{2}}{1-\psi}\right)^{\frac{\alpha}{1-\alpha}} \mathcal{K}_{t}(\psi, \varphi),
$$

where $\mathcal{K}_{t}(\psi, \varphi)=e^{g(\psi, \varphi) t}$ and $g(\psi, \varphi)=\lambda \sigma \theta\left[\frac{1}{\gamma}-\frac{\frac{\lambda}{\gamma}+\rho}{\lambda\left(1+\frac{1+\varphi}{1-\psi} \alpha\right)}\right]$.

The key point is that, because the knowledge inherent in innovations is not priced, the value of any innovation stems only from the stream of monopoly profits given by intellectual property rights. Besides, recall that in this type of equilibrium, because of the creative destruction mechanism, in each sector, at date $t$, only the latest innovator (i.e. the incumbent) receives positive profits.

\subsection{Lindahl equilibrium and social value of innovations}

\subsubsection{Definition of the Lindahl equilibrium}

Now, we focus on the main purpose of this paper, which is to answer the following questions: what is the social value of an innovation and how should it be computed? As explained above, the social value of an innovation is the optimal one. Moreover, since an innovation consists in the creation of new units of knowledge embodied in an intermediate good, one has to determine the social value of each unit of knowledge inherent in an innovation. Finally, since knowledge is a non rival good, we construct a Lindahl equilibrium (which differs significantly from the standard Schumpeterian equilibrium à la Aghion \& Howitt). The construction of this equilibrium lies on two main points. First, all rival goods - in particular intermediate goods - are priced at their marginal cost. Second, we complete the markets by pricing knowledge. This pricing goes through the following three steps.

i) Each user of knowledge pays each unit of knowledge at a personalized price (the Lindahl price) which is equal to his willingness to pay for that unit, that is, to the marginal profitability of this unit for that user. Each innovator receives the sum of these Lindahl prices for each unit of knowledge inherent in his innovation. 
ii) Since each unit of knowledge is simultaneously used by three types of economic activities, we have to define a Lindahl price for each of them. Formally, we denote by $v_{\omega t}^{Y}, v_{\omega t}^{x}$, and $v_{\omega t}^{\chi_{h}}$, $h \in \Omega$, the Lindahl prices (i.e. the instantaneous marginal profitabilities) of one unit of knowledge $\chi_{\omega t}, \omega \in \Omega$, for the final sector, for the intermediate good sector $\omega$, and for any R\&D activity $h$, respectively. Then, the instantaneous price received at date $t$ by the producer for this unit of knowledge is $v_{\omega t}=v_{\omega t}^{Y}+v_{\omega t}^{x}+v_{\omega t}^{R \& D}$, where $v_{\omega t}^{R \& D}=\int_{\Omega} v_{\omega t}^{\chi_{h}} d h$ is the instantaneous value of this unit for the whole R\&D activity of the economy. As detailed below, $v_{\omega t}^{\chi_{h}}$ is strictly positive if $\mathrm{R} \& \mathrm{D}$ activity $h$ uses knowledge $\chi_{\omega t}$, that is, if knowledge $\chi_{\omega t}$ belongs to the pool of knowledge $\mathcal{P}_{h t}$ used by R\&D activity $h$. Formally this is the case if $h \in \mathcal{D}_{\omega}$ or, equivalently, if $\omega \in \Omega_{h}$. If $h \notin \mathcal{D}_{\omega}$, then $v_{\omega t}^{\chi_{h}}$ is nil.

iii) Since knowledge is infinitely-lived, the innovator receives this instantaneous price at each instant from the date of innovation until infinity.

Note that, due to the non-convexity of the technologies of the final sector and of the R\&D activities, in which knowledge - a non rival good - is an input, R\&D expenditures must be publicly funded. Indeed the replication argument states that, in these sectors, technologies display constant returns to scale with respect to rival inputs and increasing returns to scale with respect to rival inputs and knowledge taken jointly. In a competitive market, the payment of rival inputs fully exhausts revenue and firms are thus unable to pay for the knowledge they use. Hence, such an equilibrium (in which rival goods markets are perfectly competitive) would exist only if the purchase of knowledge is entirely financed by public expenditures.

From the first welfare theorem, we know that the Lindahl equilibrium is Pareto optimal (e.g. Mas-Colell, Whinston \& Green 1995 - Ch. 16 - P. 570); this result will indeed be verified within this endogenous growth framework (see Propositions 2 and 5). Hence, as mentioned above, we are sure that the value of knowledge computed in this equilibrium is the optimal one, that is, the social one. Consequently, we use the superscript "o" (introduced above in Subsection 2.2) for all variables associated to this equilibrium. The Lindahl equilibrium is formally defined as follows:

Definition 4. The Lindahl equilibrium consists of time paths of set of prices

$$
\left\{\left(w_{t}^{o}, r_{t}^{o},\left\{q_{\omega t}^{o}\right\}_{\omega \in \Omega},\left\{v_{\omega t}^{Y o}\right\}_{\omega \in \Omega},\left\{v_{\omega t}^{x o}\right\}_{\omega \in \Omega},\left\{v_{\omega t}^{\chi_{h} o}\right\}_{\omega \in \Omega, h \in \Omega}\right)\right\}_{t=0}^{\infty}
$$

and of quantities

$$
\left\{\left(c_{t}^{o}, Y_{t}^{o},\left\{x_{\omega t}^{o}\right\}_{\omega \in \Omega}, L_{t}^{Y o},\left\{l_{\omega t}^{o}\right\}_{\omega \in \Omega},\left\{\chi_{\omega t}^{o}\right\}_{\omega \in \Omega}\right)\right\}_{t=0}^{\infty}
$$

such that: the representative household maximizes his utility; firms (final good producer, intermediate goods producers, RED activities) maximize their profits; all rival goods markets (final good market, labor market, intermediate goods markets, and financial market) are perfectly competitive and clear; each user of knowledge pays each unit of knowledge at its Lindahl price; for each unit of knowledge inherent in his innovation, the innovator receives at each date the sum of the Lindahl prices of this unit from the date of innovation until infinity; and all knowledge expenditures are funded by the government.

In Subsection 3.2.5 below, we will discuss the realism, the applicability and the relevancy of this equilibrium. From this definition, the social value of innovations can now be determined.

\subsubsection{Social value of one unit of knowledge and social value of innovations}

According to Definition 4, we can first define the social value of each unit of knowledge:

Definition 5. Consider an innovation at date $t$ in any sector $\omega, \omega \in \Omega$. The social value of one unit of knowledge $\chi_{\omega t}$ inherent in this innovation at date $t$ is the discounted sum of the sum of the Lindahl prices of this unit:

$$
V_{\omega t}^{o}=\int_{t}^{\infty} v_{\omega \tau}^{o} e^{-\int_{t}^{\tau} r_{u}^{o} d u} d \tau, \text { where } v_{\omega t}^{o}=v_{\omega t}^{Y o}+v_{\omega t}^{x o}+v_{\omega t}^{R \& D o}
$$

We can now define the social value of an innovation. As explained above in Definition 1, we know that an innovation involves an increase in knowledge of $\Delta \chi_{\omega t}$ new units. Accordingly, one gets the following definition:

Definition 6. Consider an innovation at date $t$ in any sector $\omega, \omega \in \Omega$. Its social value is

$$
\mathcal{V}_{\omega t}^{o}=V_{\omega t}^{o} \Delta \chi_{\omega t}, \text { where } V_{\omega t}^{o} \text { is given by (10) }
$$


Definition 6 provides, in a Schumpeterian growth model, a formal expression that corresponds precisely to the statement of Green \& Scotchmer (1995) when they write that "the social value of an early innovation includes the net social value of the applications it facilitates". In the Lindahl equilibrium, at any date $t$, all innovators, whether the incumbent or any previous one, receive positive income; recall that, by contrast, in the Schumpeterian equilibrium only the latest innovator receives positive income (monopoly profits).

\subsubsection{Agents' behaviors and Lindahl prices}

In order to clarify the concept of Lindahl equilibrium, we now present the agents' behaviors. In particular, we determine the Lindahl prices of each unit of knowledge $\chi_{\omega t}$ produced in any sector $\omega$.

- In the final sector, the competitive firm maximizes its profit (purchases of knowledge not included) $\pi_{t}^{Y}=Y_{t}-w_{t} L_{t}^{Y}-\int_{\Omega} q_{\omega t} x_{\omega t} d \omega\left(\right.$ where $\left.Y_{t}=\left(L_{t}^{Y}\right)^{1-\alpha} \int_{\Omega} \chi_{\omega t}\left(x_{\omega t}\right)^{\alpha} d \omega\right)$ with respect to $L_{t}^{Y}$ and $x_{\omega t}$. The first-order conditions yield

$$
w_{t}=(1-\alpha) \frac{Y_{t}}{L_{t}^{Y}} \text { and } q_{\omega t}=\alpha\left(L_{t}^{Y}\right)^{(1-\alpha)} \chi_{\omega t}\left(x_{\omega t}\right)^{\alpha-1}, \forall \omega \in \Omega
$$

Moreover, at each date $t$, the marginal profitability (i.e. the Lindahl price) of one unit of knowledge $\chi_{\omega t}$ produced in any sector $\omega$ for the final sector is

$$
v_{\omega t}^{Y}=\frac{\partial \pi_{t}^{Y}}{\partial \chi_{\omega t}}=\left(L_{t}^{Y}\right)^{(1-\alpha)}\left(x_{\omega t}\right)^{\alpha}, \forall \omega \in \Omega
$$

- In any intermediate sector $\omega, \omega \in \Omega$, as explained above, we assume in this framework that, contrary to the standard endogenous growth literature, intermediate goods producers behave competitively. The profit on the sale of intermediate good $\omega$ (purchases of knowledge not included) is $\pi_{t}^{x_{\omega}}=\left(q_{\omega t}-\chi_{\omega t}\right) x_{\omega t}$. Maximizing this profit with respect to $x_{\omega t}$ implies that it is driven to zero. Consequently, one has $q_{\omega t}=\chi_{\omega t}$; substituting in (12) implies that $\chi_{\omega t}=\alpha\left(L_{t}^{Y}\right)^{(1-\alpha)} \chi_{\omega t}\left(x_{\omega t}\right)^{\alpha-1}$. Finally, one gets

$$
q_{\omega t}=\chi_{\omega t} \text { and } x_{\omega t}=x_{t}=\alpha^{\frac{1}{1-\alpha}} L_{t}^{Y}, \forall \omega \in \Omega
$$

In (14), it is obvious that, contrary to what occurs in the Schumpeterian equilibrium, intermediate goods are priced at their marginal cost; one also gets the usual result on the symmetric use of intermediate goods.

Furthermore, at each date $t$, the marginal profitability (i.e. Lindahl price) of one unit of knowledge $\chi_{\omega t}$ produced in any sector $\omega$ for the production of intermediate good $\omega$ is

$$
v_{\omega t}^{x}=\frac{\partial \pi_{t}^{x_{\omega}}}{\partial \chi_{\omega t}}=-x_{\omega t}, \forall \omega \in \Omega
$$

One may wonder why this Lindahl price is negative. As explained after (6), the intermediate good production technology accounts for increasing complexity. In fact, the production of a new unit of knowledge in sector $\omega$ clearly increases $\chi_{\omega t}$, the stock of knowledge in this sector. This leads to an increase in the production cost of intermediate good $\omega$, which embodies this larger stock of knowledge.

- In any intermediate sector $h, h \in \Omega$, given the technology of production of innovations (2), the expected profit of the R\&D activity (purchases of knowledge not included) is $\pi_{t}^{\chi_{h}}=\lambda l_{h t} \mathcal{V}_{h t}-w_{t} l_{h t}$, where $\mathcal{V}_{h t}=V_{h t} \Delta \chi_{h t}$ is the value of an innovation in sector $h$ (i.e. the value of each unit of knowledge inherent in this innovation, $V_{h t}$, multiplied by the $\Delta \chi_{h t}$ new units of knowledge created at the time of the innovation). Maximizing this profit with respect to $l_{h t}$ implies that it is driven to zero; that gives

$$
w_{t}=\lambda \mathcal{V}_{h t}=\lambda V_{h t} \Delta \chi_{h t}, \forall h \in \Omega
$$

Moreover, at each date $t$ and for any $\mathrm{R} \& \mathrm{D}$ activity $h, h \in \Omega$, the marginal profitability (i.e. the Lindahl price) of one unit of knowledge $\chi_{\omega t}$ produced in $\mathrm{R} \& \mathrm{D}$ activity $\omega, \omega \in \Omega$, is

$$
v_{\omega t}^{\chi_{h}}=\frac{\partial \pi_{t}^{\chi_{h}}}{\partial \chi_{\omega t}}=\lambda l_{h t} V_{h t} \frac{\partial \Delta \chi_{h t}}{\partial \chi_{\omega t}}, \forall \omega \in \Omega, \forall h \in \Omega
$$


In the present model, we consider explicitly inter-sectoral knowledge spillovers. Accordingly, since $\Delta \chi_{h t}$ depends positively on the pool of knowledge $\mathcal{P}_{h t}$ used by $\mathrm{R} \& \mathrm{D}$ activity $h$, the value of the partial derivative $\partial \Delta \chi_{h t} / \partial \chi_{\omega t}$ depends on whether the stock of knowledge $\chi_{\omega t}$ belongs to the pool $\mathcal{P}_{h t}$, or not (i.e. on whether R\&D activity $h$ uses the stock $\chi_{\omega t}$, or not). If R\&D activity $h$ uses the stock $\chi_{\omega t}, \partial \Delta \chi_{h t} / \partial \chi_{\omega t}$ is positive and from Assumption 2 and Lemma 2 one has $\partial \Delta \chi_{h t} / \partial \chi_{\omega t}=\sigma$; if not, it is zero. ${ }^{17}$ Thus, (17) writes

$$
v_{\omega t}^{\chi_{h}}=\frac{\partial \pi_{t}^{\chi_{h}}}{\partial \chi_{\omega t}}=\lambda \sigma l_{h t} V_{h t} \frac{\partial \mathcal{P}_{h t}}{\partial \chi_{\omega t}}=\left\{\begin{array}{l}
\lambda \sigma l_{h t} V_{h t}, \text { if } h \in \mathcal{D}_{\omega} \\
0, \text { if } h \notin \mathcal{D}_{\omega}
\end{array} \quad, \forall \omega \in \Omega\right.
$$

In Lemma 3, we recapitulate the results relative to the marginal profitabilities of one unit of knowledge $\chi_{\omega t}, \omega \in \Omega$, given by (13), (15) and (18), obtained by studying the individual behaviors of the various users of this unit.

Lemma 3. At date $t$, the Lindahl prices (marginal profitabilities) of one unit of knowledge $\chi_{\omega t}$ produced in any sector $\omega$, for the final good sector, the intermediate sector $\omega, \omega \in \Omega$, and the RED sector $h, h \in \Omega$, respectively are

$$
v_{\omega t}^{Y}=\left(L_{t}^{Y}\right)^{(1-\alpha)}\left(x_{\omega t}\right)^{\alpha}, v_{\omega t}^{x}=-x_{\omega t} \text { and } v_{\omega t}^{\chi_{h}}=\left\{\begin{array}{l}
\lambda \sigma l_{h t} V_{h t}, \text { if } h \in \mathcal{D}_{\omega} \\
0, \text { if } h \notin \mathcal{D}_{\omega}
\end{array} \quad, \forall \omega \in \Omega\right.
$$

The instantaneous price received by the producer of this unit of knowledge $\chi_{\omega t}$ is

$$
v_{\omega t}=v_{\omega t}^{Y}+v_{\omega t}^{x}+v_{\omega t}^{R \& D}, \text { where } v_{\omega t}^{R \& D}=\int_{\Omega} v_{\omega t}^{\chi_{h}} d h, \forall \omega \in \Omega
$$

Now that we have presented the basic concepts relative to the Lindahl equilibrium, we can derive the main results. They are given below in 3.2.4. All intermediate computations are detailed in Appendix 5.4.

\subsubsection{Lindahl equilibrium and social value of innovations: characterization}

Since the Lindahl equilibrium is Pareto optimal, the partition of labor, the quantities of intermediate goods and the growth rates are the optimal ones (given in Proposition 2). ${ }^{18}$ The system of prices that sustains the first-best is provided in Proposition 5 (as previously, the superscript "o" is used for "social optimum").

Proposition 5. In the Lindahl equilibrium, the system of prices is the following.

- The prices of rival goods are $w_{t}^{o}=(1-\alpha) \alpha^{\frac{\alpha}{1-\alpha}} \mathcal{K}_{t}^{o} ; r_{t}^{o}=\frac{\lambda \sigma \theta}{\gamma} ; q_{\omega t}^{o}=q_{t}^{o}=\chi_{t}^{o}=\frac{\mathcal{K}_{t}^{o}}{\gamma L}, \forall \omega \in \Omega$, where $\mathcal{K}_{t}^{o}=e^{g^{o} t}$ and $g^{o}=\frac{\lambda \sigma \theta}{\gamma}-\rho$.

- Each unit of knowledge is priced as follows:

- The Lindahl prices of one unit of knowledge $\chi_{\omega t}$ for the final good sector, for the intermediate sector $\omega$, and for the $R \mathscr{E} D$ activity of intermediate sector $h, h \in \Omega$, are respectively

$$
\begin{gathered}
v_{\omega t}^{Y o}=\alpha^{\frac{\alpha}{1-\alpha}} \frac{\rho \gamma L}{\lambda \sigma \theta} ; v_{\omega t}^{x o}=-\alpha^{\frac{1}{1-\alpha}} \frac{\rho \gamma L}{\lambda \sigma \theta} \\
\text { and } v_{\omega t}^{\chi_{h} o}=\left\{\begin{array}{l}
\frac{(1-\alpha) \alpha^{\frac{\alpha}{1-\alpha}}}{\theta}\left(L-\frac{\rho \gamma L}{\lambda \sigma \theta}\right), \text { if } h \in \mathcal{D}_{\omega} \\
0, \text { if } h \notin \mathcal{D}_{\omega}
\end{array}, \forall \omega \in \Omega .\right.
\end{gathered}
$$

\footnotetext{
${ }^{17}$ Indeed, one has the following:

$$
\frac{\partial \Delta \chi_{h t}}{\partial \chi_{\omega t}}=\sigma \frac{\partial \mathcal{P}_{h t}}{\partial \chi_{\omega t}}=\sigma \frac{\partial\left(\int_{\Omega_{h}} \chi_{j t} d j\right)}{\partial \chi_{\omega t}}, \forall \omega \in \Omega
$$

Moreover, $\frac{\partial\left(\int_{\Omega_{h}} \chi_{j t} d j\right)}{\partial \chi_{\omega t}}=1$ if the knowledge $\chi_{\omega t}$ belongs to the pool $\mathcal{P}_{h t}$, that is, if $\omega \in \Omega_{h}$, which is equivalent to $h \in \mathcal{D}_{\omega}$. If $\omega \notin \Omega_{h}$, then $\frac{\partial\left(\int_{\Omega_{h}} \chi_{j t} d j\right)}{\partial \chi_{\omega t}}=0$.

${ }^{18}$ This result is indeed verified in Appendix 5.4; see (66).
} 
- The instantaneous income received by the innovator for each unit of knowledge $\chi_{\omega t}$ he has produced is

$$
v_{\omega t}^{o}=v_{\omega t}^{Y o}+v_{\omega t}^{x o}+v_{\omega t}^{R \& D o}=v^{o}=(1-\alpha) \alpha^{\frac{\alpha}{1-\alpha}} L, \forall \omega \in \Omega,
$$

where $v_{\omega t}^{R \& D o}$ is the instantaneous value of one unit of knowledge $\chi_{\omega t}$ for the whole R\&D activity of the economy:

$$
v_{\omega t}^{R \& D o}=\int_{\Omega} v_{\omega t}^{\chi_{h} o} d h=(1-\alpha) \alpha^{\frac{\alpha}{1-\alpha}}\left(L-\frac{\rho \gamma L}{\lambda \sigma \theta}\right), \forall \omega \in \Omega .
$$

Proof. See Appendix 5.4.

The Lindahl equilibrium allows us to value knowledge. In the following proposition, we provide $V_{\omega t}^{o}$, the social value of one unit of knowledge $\chi_{\omega t}$ at date $t$ (as seen in Definition 5 , it is the discounted sum of the sum of the Lindahl prices) and $\mathcal{V}_{\omega t}^{o}=V_{\omega t}^{o} \Delta \chi_{\omega t}$, the social value of an innovation in sector $\omega$ (as seen in Definition 6 , it is the value of the increase in knowledge $\Delta \chi_{\omega t}$ inherent in this innovation).

Proposition 6. Value of knowledge in the Lindahl equilibrium.

i) At date $t$, the social value of one unit of knowledge $\chi_{\omega t}$ in any sector $\omega$, is

$$
V_{\omega t}^{o}=V^{o}=\frac{(1-\alpha) \alpha^{\frac{\alpha}{1-\alpha}} \gamma L}{\lambda \sigma \theta}, \forall \omega \in \Omega
$$

ii) Consider an innovation in sector $\omega$ at date $t$; its social value is

$$
\mathcal{V}_{\omega t}^{o}=\mathcal{V}_{t}^{o}=\frac{(1-\alpha) \alpha^{\frac{\alpha}{1-\alpha}}}{\lambda} \mathcal{K}_{t}^{o}, \text { where } \mathcal{K}_{t}^{o}=e^{g^{o} t} \text { and } g^{o}=\frac{\lambda \sigma \theta}{\gamma}-\rho, \forall \omega \in \Omega
$$

Proof. See Appendix 5.4. $V_{\omega t}^{o}$ is derived in equation (63) (alternatively, it can also be computed from its definition given in (11), using the expressions of the instantaneous social value, $v_{\omega t}^{o}$, and of the interest rate, $r_{t}^{o}$, provided in Proposition 5). $\mathcal{V}_{\omega t}^{o}$ is derived in equation (67).

In the following corollary, we provide a somehow intuitive result that contributes to explain the link between the private value and the social value of an innovation.

Corollary. The optimal private value of innovations - i.e. the private value when the two distortions present in the Schumpeterian equilibrium (namely the monopoly distortion and the market incompleteness) are corrected - is their social value: $\Pi_{t}^{x}\left(\psi^{o}, \varphi^{o}\right)=\mathcal{V}_{t}^{o}$.

Proof. The proof is straightforward. Plugging the optimal tools (derived in the corollary to Proposition 3) into the expression of the private value of innovations given in Proposition 4, one gets the expression of the social value of innovations given in Proposition 6.

Introducing the concept of Lindahl equilibrium allows us to understand what is fundamentally the social value of an innovation. Indeed, consider the Schumpeterian equilibrium in which the two public tools, $\psi$ and $\varphi$, are set at their optimal level. In this case, as proven in the corollary to Proposition 6, the discounted sum of the expected monopoly profits on intermediate goods embodying knowledge (a non rival good) is exactly equal to the discounted sum of the sum of the Lindahl prices of this knowledge. In other words, once the monopoly distortion has been corrected in the Schumpeterian equilibrium, it is equivalent, from a welfare perspective, to subsidize (or tax) optimally $\mathrm{R} \& \mathrm{D}$ or to complete the markets by pricing each unit of knowledge at its Lindahl prices.

\subsubsection{Realism, applicability and relevancy of the Lindahl equilibrium}

In this subsection, we explain why, even though the Lindahl equilibrium is not realistic, it is yet a relevant concept to analyze many issues involving the presence of knowledge, a non rival good, within a R\&D-based endogenous growth model. The Lindahl equilibrium does not provide 
a realistic decentralized economy, basically because the non-rivalry property of knowledge raises problems that this equilibrium does not enable us to solve.

First, as explained above (see before Definition 4), the existence of the Lindahl equilibrium requires that the purchase of knowledge is entirely financed by public expenditures; this is strongly at odds with empirical evidences. See, for instance, Kaizuka (1965), Manning, Markusen \& Mc Millan (1985), or Romer (1990). In order to tackle this issue, one should consider a concept of equilibrium in which firms get strictly positive profits on the rival goods they sell so as to enable them to pay for the knowledge they use. Introducing imperfect competition for rival goods markets is a possible solution: for instance, Chantrel, Grimaud \& Tournemaine (2012) use Cournot competition with free entry in that respect.

Second, the fact that knowledge is a non rival good also raises standard problems of public economics. In particular, how to verify which agents use knowledge (verification problem), how can their willingness to pay be revealed (information problem), how to exclude agents who do not pay to use knowledge (exclusion problem). For instance, in their analysis of the issues involved by the presence of public goods and by their funding, Mas-Colell, Whinston \& Green (1995 Ch. 11 and Ch. 16) argue that "the fact that the prices are personalized means that personal, private information is required" and that "this [type of equilibrium] requires that the public good be excludable". As a matter of fact, the applicability of Lindahl pricing requires that knowledge sellers are able to discriminate perfectly among users, which can obviously be difficult to implement.

These issues of realism are undoubtedly crucial; yet they remain out of the scope of the present paper. Indeed, what matters here is that the concept of Lindahl equilibrium is a theoretical benchmark. As seen above, it allows us to compute the system of prices that sustains the firstbest optimum, and thus to unveil the social value of innovations. Moreover, in Subsection 3.3 below, the comparison between the Lindahl and the Schumpeterian equilibria reveals how the market incompleteness considered in the Schumpeterian equilibrium is the fundamental cause of the inappropriateness of $\mathrm{R} \& \mathrm{D}$ incentives, and thus of its Pareto non-optimality. Finally, as mentioned in the introduction, one observes that nowadays, knowledge is de facto priced in an economy that progressively dematerializes; one can think that the Lindahl equilibrium is a relevant benchmark to understand how knowledge is exchanged in this type of weightless economy. The issue of formalizing how knowledge is exchanged (e.g. through markets, contracts, or other types of organizations) is left for further research.

\subsection{Lindahl equilibrium versus Schumpeterian equilibrium}

We now compare the Schumpeterian equilibrium to the Lindahl one. Let us first recall that an innovation in any given sector involves the creation of a flow of new knowledge, which increases the stock of knowledge previously embodied in the intermediate good produced in this sector. The type of incentives differ in the two equilibria because $R \& D$ is not funded the same way. In the Schumpeterian equilibrium, when an innovator (i.e. a producer of new knowledge) sells an intermediate good (a rival good), he indirectly sells knowledge (a non rival good). Therefore, $\mathrm{R} \& \mathrm{D}$ investments are indirectly funded by monopoly profits on a rival good embodying knowledge; see $\pi_{\tau}^{x_{\omega}}(\psi, \varphi)$ in the private value of an innovation given in (9). In the Lindahl equilibrium, each intermediate good is priced at its marginal cost (see (14)) and R\&D investments are directly funded by pricing knowledge; see the Lindahl prices, $v_{\omega t}^{Y o}, v_{\omega t}^{x o}$ and $v_{\omega t}^{\chi_{h} o}$, in the social value of an innovation given in (11).

As shown in the corollary to Proposition 3, we know that two public tools are sufficient to implement the first-best in the Schumpeterian equilibrium. What are exactly the two market failures associated with these tools? In fact, the comparison between the two equilibria allows us to identify them clearly. Indeed, the definitions of the two equilibria reveal two differences. First, the market for intermediate goods is competitive in the Lindahl equilibrium whereas it is monopolistic in the Schumpeterian one. Second, and fundamentally, markets are complete in the Lindahl equilibrium (knowledge is priced) whereas there is no market for knowledge in the Schumpeterian one (knowledge is not priced).

Comparing the two equilibria shows that market incompleteness implies three issues resulting in the fact that the private and the social values of innovations are likely to differ. This turns out to matter particularly when it comes to study R\&D incentives in the presence of sequential and cumulative innovations, and to revisit the issue of Pareto non-optimality arising in the Schumpeterian equilibrium. 


\subsubsection{Market incompleteness and R\&D incentives}

The three issues (two of them are static, the third one is dynamic) stemming from market incompleteness - and identified by comparing the two equilibria - relate to three variables of the economy: the quantities of knowledge sold, the prices of this knowledge, and the period during which innovators are paid.

a) The quantities of knowledge sold - whether indirectly, as in the Schumpeterian equilibrium, or directly, as in the Lindahl equilibrium - differ in the two equilibria.

In the Schumpeterian equilibrium, an entrant (i.e. the latest innovator) sells to the final sector an intermediate good that embodies the whole stock of knowledge, $\chi_{\omega t}$, created in the sector so far (i.e. including the knowledge produced by its predecessors) and thus benefits from previously conducted R\&D. In other words, the innovator indirectly sells this stock of knowledge. This can be shown as follows. First, the private value of an innovation $\Pi_{\omega t}^{x}(\psi, \varphi)$ depends on the instantaneous profits $\pi_{\tau}^{x_{\omega}}(\psi, \varphi)$. See $(9)$ in Definition 3. Second, at each date $t$, due to the well known issue of appropriability (we return to this issue below), the instantaneous profit is only a fraction of the net surplus generated by intermediate good $\omega$. Third, computing this surplus (see (19) below), we show that it depends on the whole stock of knowledge, $\chi_{\omega t}$.

In contrast, in the Lindahl equilibrium, the knowledge sold by an innovator includes only the incremental knowledge, $\Delta \chi_{\omega t}$, associated to the innovation. Indeed, the social value of an innovation, $\mathcal{V}_{\omega t}^{o}$, depends only on the flow of knowledge $\Delta \chi_{\omega t}$. See (11) in Definition 6.

Basically, in the Schumpeterian equilibrium, the latest innovator implicitly appropriates and sells knowledge that he did not produce. In terms of R\&D incentives provided in the Schumpeterian equilibrium, this first static issue tends to lead to an excessive allocation of resources in R\&D activity.

b) The prices of knowledge paid to an innovator - whether implicitly, as in the Schumpeterian equilibrium, or explicitly, as in the Lindahl equilibrium - differ in the two equilibria. Indeed, knowledge is not sold to the same economic agents in the two equilibria.

In the Schumpeterian equilibrium, the innovator's behavior depends on the fact that the knowledge embodied in the intermediate good has an impact on two agents. First, the final sector; indeed, it is the only agent to whom the intermediate good - and thus the knowledge embodied in it - is sold. Second, the innovator himself, since he produces this intermediate good and since his production costs increase with the level of knowledge accumulated in the sector. See the expressions of the technology of intermediate good production (6) and of monopoly profits (8). This can be seen more formally below in the first part of the expression (19) of the surplus.

On the contrary, as explained in Section 3.2 (in particular, Lemma 3 and Proposition 5), in the Lindahl equilibrium each unit of knowledge inherent in an innovation is valued for all of its users: for the producer of the final good $\left(v_{\omega t}^{Y o}\right)$, for the producer of the intermediate good embodying this knowledge $\left(v_{\omega t}^{x o}\right)$, but also for all the R\&D activities using this knowledge - the one of the intermediate sector in which it has been produced $\left(v_{\omega t}^{\chi_{\omega} o}\right)$, as well as the ones of a more or less wide range of intermediate sectors $\left(v_{\omega t}^{\chi_{h} o}, \forall h \in \mathcal{D}_{\omega}\right)$.

Obviously, in the Schumpeterian equilibrium, each innovator neglects the fact that his innovation may be of some use for producing new knowledge in various R\&D activities: it neglects the Lindahl prices $v_{\omega t}^{\chi_{h} o}$. This can be seen more formally below in the second part of the expression (19) of the surplus. In terms of $R \& D$ incentives, the fact that the Schumpeterian equilibrium considers only the private value of innovations - and that this value disregards knowledge spillovers - tends to yield an insufficient allocation of resources in R\&D. Thereupon, one can observe that the more intense the knowledge spillovers (i.e. the larger $\sigma \theta$ ), the higher the value of one unit of knowledge for R\&D activities: from Proposition 5, one has $v_{\omega t}^{R \& D o}=\int_{\mathcal{D}_{\omega}} v_{\omega t}^{\chi_{h} o} d h=(1-\alpha) \alpha^{\frac{\alpha}{1-\alpha}}\left(L-\frac{\rho \gamma L}{\lambda \sigma \theta}\right)$. Thus, the higher the knowledge spillovers intensity $\sigma \theta$, the more this negligence - which results from market incompleteness - will be likely to lead to an insufficient allocation of resources in R\&D. We provide some more details on this matter below in 3.3.2; in particular, see (21) and Figure 1.

The issues a) and b) can be presented more formally by comparing the instantaneous revenue of an innovator in the Schumpeterian equilibrium and in the Lindahl one. In that respect, let us compute the optimal value of an intermediate good in the Schumpeterian equilibrium; it is given by the instantaneous net surplus generated by intermediate good $\omega$ at date $t$ once the first-best optimum is implemented. In fact, it occurs that this social surplus is equal to the value of the stock of knowledge $\chi_{\omega t}^{o}$ embodied in it for the user and the producer of this good (i.e. for the final 
sector and the intermediate sector $\omega):^{19}$

$$
S_{\omega t}^{o}=\left(v_{\omega t}^{Y o}+v_{\omega t}^{x o}\right) \chi_{\omega t}^{o}=\left(v_{\omega t}^{o}-v_{\omega t}^{R \& D o}\right) \chi_{\omega t}^{o}
$$

It clearly appears that this surplus is different from the instantaneous value of the knowledge inherent in an innovation in the Lindahl equilibrium, which is $v_{\omega t}^{o} \Delta \chi_{\omega t}$, that is, $\left(v_{\omega t}^{Y o}+v_{\omega t}^{x o}+v_{\omega t}^{R \& D o}\right) \Delta \chi_{\omega t}$. This corroborates the two static issues put forward in a) and b) to explain why the R\&D incentives in the Schumpeterian equilibrium are not the optimal ones. Indeed, the surplus $S_{\omega t}^{o}$ does not take into account neither the proper quantity of knowledge $\left(\chi_{\omega t}\right.$ instead of $\left.\Delta \chi_{\omega t}\right)$, nor the proper price $\left(v_{\omega t}^{R \& D o}\right.$ is missing).

To conclude on the static issues implying that the R\&D incentives in the Schumpeterian equilibrium are not the optimal ones, note that, even if the surplus was reflecting accurately the instantaneous value of an innovation, the incentives would not be adequate. Indeed, the monopoly does not extract the whole surplus. This issue of appropriability - which has been extensively studied in the literature (e.g. Aghion \& Howitt 1992, 1998 - Ch. 2, or Acemoglu 2009 - Ch. 14) leads to an insufficient allocation of resources in R\&D.

c) Finally, let us consider the dynamic issue. The two equilibria differ regarding the period during which an innovation provides revenues to its producer.

In the Schumpeterian equilibrium, since there is no distinction between an intermediate good and the knowledge embodied in it, one neglects that goods disappear while knowledge persists. Indeed, in each intermediate sector, the latest innovator (a producer of knowledge) monopolizes the production and sale of the intermediate good (which embodies knowledge) until replaced by the next innovator. This creative destruction mechanism implies that, in each sector, the patent owner has a monopoly the lifespan of which is finite in average. This can be seen in Definition 3: in the expression (9) of the private value of an innovation, there is a discount factor that includes the term $\lambda l_{\omega u}(\psi, \varphi)$ (the rate of creative destruction). The presence of this term implies that the period during which an innovation yields some return is finite in average.

In the Lindahl equilibrium, in each intermediate sector, the instantaneous profit of the intermediate good producer is nil because of perfect competition and, as in the Schumpeterian case, this good disappears when a higher quality good can be produced (i.e. consecutively to each innovation). However, the innovator receives revenues forever because each unit of knowledge constituting his innovation is infinitely-lived and is priced at each instant of time: at each date $t$, each innovator receives the sum of the Lindahl prices $v_{\omega t}$. This clearly appears in Definitions 5 and 6 . Definition 6 gives the expression of the social social value of an innovation (see (11)): $\mathcal{V}_{\omega t}^{o}=V_{\omega t}^{o} \Delta \chi_{\omega t}$. Definition 5 gives the social value of one unit of knowledge $V_{\omega t}^{o}$ (see (10)), in which the discount factor only includes the interest rate: the term $\lambda l_{\omega u}(\psi, \varphi)$ does not appear. Basically, this means that the innovator receives revenues forever.

Regarding R\&D incentives provided within the Schumpeterian equilibrium, this leads to an insufficient allocation of resources in R\&D.

This analysis allows us to shed a new light on the issue of Pareto non-optimality in R\&Dbased endogenous growth models. Many of them predict that the decentralized economy can lead to either an insufficient or an excessive level of resources devoted to R\&D activity, and thus to an insufficient or excessive growth. This well-known result has been extensively discussed in the growth literature, both in vertical differentiation class of models (e.g. Grossman \& Helpman 1991; Aghion \& Howitt 1992; Segerstrom 1998; Li 2003) ${ }^{20}$ and in expanding variety models à la Romer (e.g. Benassy 1998; Jones \& Williams 2000; Alvarez-Pelaez \& Groth 2005).

\footnotetext{
${ }^{19}$ At the first-best, the inverse demand function of intermediate good $\omega$ at date $t$ is obtained from (12). One has $q_{\omega t}^{o}\left(x_{\omega t}\right)=\alpha\left(L_{t}^{Y o}\right)^{(1-\alpha)} \chi_{\omega t}^{o}\left(x_{\omega t}\right)^{\alpha-1}$, where $L_{t}^{Y o}$ and $\chi_{\omega t}^{o}$ are given in Proposition 2. Then, the instantaneous net social surplus generated by the production and use of this intermediate good is $S_{\omega t}^{o}=\int_{0}^{x_{\omega t}^{o}} q_{\omega t}^{o}(x) d x-q_{\omega t}^{o} x_{\omega t}^{o}$, where $x_{\omega t}^{o}$ and $q_{\omega t}^{o}$ are given in Propositions 2 and 5, respectively. After computation, one gets $S_{\omega t}^{o}=(1-\alpha) \alpha^{\frac{\alpha}{1-\alpha}} \frac{\rho \gamma L}{\lambda \sigma \theta} \chi_{\omega t}^{o}$. Moreover, in Proposition 5, we have shown that the Lindahl prices of one unit of knowledge $\chi_{\omega t}$ for the final sector and for the intermediate sector $\omega$ are $v_{\omega t}^{Y o}=\alpha^{\frac{\alpha}{1-\alpha}} \frac{\rho \gamma L}{\lambda \sigma \theta}$ and $v_{\omega t}^{x o}=-\alpha^{\frac{1}{1-\alpha}} \frac{\rho \gamma L}{\lambda \sigma \theta}$, respectively. This yields the first expression of the surplus in (19). Finally, since $v_{\omega t}^{o}=v_{\omega t}^{Y o}+v_{\omega t}^{x o}+v_{\omega t}^{R \& D o}$, one has its second expression.

${ }^{20}$ One can find several complementary approaches trying to understand why the equilibrium allocation can either be sub-optimal or over-optimal in models with vertical innovations. The first one could be described as market oriented: Aghion \& Howitt $(1992,1998)$ for instance, focus on the various market failures of the equilibrium considered to explain why Pareto non-optimality may arise. Basically, it is generally argued that the surplus appropriability problem and knowledge spillovers both promote under-investment in R\&D whereas creative destruction and duplication effects both foster over-investment in R\&D. In a complementary approach, Grossman \& Helpman (1991) and Segerstrom (1998), among others, relate the fact that there is too little or too much R\&D to the "size of innova-
} 
What is new in our approach is to use the Lindahl equilibrium in order to show that nonoptimality basically stems from market incompleteness. Indeed, besides the appropriability effect, we have identified three consequences of incompleteness: the first one - a) - leads to too much R\&D, whereas the two others - b) and c) - lead to too little R\&D. These three points can somehow be related to two effects often mentioned in the standard literature, namely, the "business stealing" and "intertemporal knowledge spillover" effects. Note that there does not seem to be a consensus on the labeling of these effects. In the seminal paper by Aghion \& Howitt (1992), these two effects are described as follows.

Business stealing effect: "The private research firm does not internalize the loss to the previous monopolist caused by an innovation. In contrast, the social planner takes into account that an innovation destroys the social return from the previous innovation."

Intertemporal knowledge spillover effect: "The social planer takes into account that the benefit to the next innovation will continue forever, whereas the private research firm attaches no weight to the benefits that accrue beyond the succeeding innovation."

For instance, the business stealing effect in Aghion \& Howitt (1992) could be interpreted as a combination of our points a) and c). In the same way, one could interpret the intertemporal knowledge spillover effect as a combination of our points b) and c). One could probably use the three points above to shed a new light on similar concepts developed in other papers in the literature.

\subsubsection{Social value of innovations versus private value of innovations}

Going further in the analysis, we now compare the social and the private values of innovations. The social value of innovations $\mathcal{V}_{\omega t}^{o}$ has been determined thanks to the Lindahl prices (see Proposition 6 ). It is the value that should be taken into account by innovators, whereas they consider the private value of innovations $\Pi_{\omega t}^{x}(\psi, \varphi)$ in the Schumpeterian equilibrium. In order to focus the analysis on market incompleteness, we consider $\Pi_{\omega t}^{x}(\psi, \varphi)$ (given in Proposition 4) in the case in which the monopoly distortion is corrected by setting $\psi=\psi^{o}=1-\alpha$, and in which there is laisser faire regarding $\mathrm{R} \& \mathrm{D}(\varphi=0)$. Then, as shown in the following result, $\mathcal{V}_{\omega t}^{o}$ appears as the pivotal value of innovations: ${ }^{21}$

$$
\Pi_{\omega t}^{x}\left(\psi^{o}, 0\right) \lesseqgtr \mathcal{V}_{\omega t}^{o} \Leftrightarrow g\left(\psi^{o}, 0\right) \lesseqgtr g^{o} \Leftrightarrow \varphi^{o} \gtreqless 0, \forall \omega, \forall t
$$

Fundamentally, in (20) we show that, due to incompleteness, the allocation of labor in R\&D activity - and thus the growth rate - is sub-optimal (resp. over-optimal) if and only if the private value of innovations is lower (resp. greater) than their social value. This also explains why $\varphi^{\circ}$ can be a subsidy or a tax.

Furthermore, the intensity of knowledge spillovers, $\sigma \theta$, plays a key part in the understanding of the previous result. For instance, in the Schumpeterian equilibrium, the allocation of labor in $\mathrm{R} \& \mathrm{D}$ does not depend on $\sigma \theta$, whereas in the Lindahl equilibrium (i.e. at the first-best optimum), it does. Indeed, one has $l\left(\psi^{o}, 0\right)=1 / \gamma-(\lambda / \gamma+\rho) / 2 \lambda=1 / 2 \gamma-\rho / 2 \lambda$ and $l^{o}=1 / \gamma-\rho / \lambda \sigma \theta$, respectively. Consequently, the higher $\sigma \theta$, the higher the $\mathrm{R} \& \mathrm{D}$ effort should be; yet, the $\mathrm{R} \& \mathrm{D}$ incentives in the Schumpeterian equilibrium do not imply this. As underlined above, the basic

tions" (i.e. to the height of the jumps on the quality ladder) but do not consider inter-sectoral knowledge spillovers. Grossman \& Helpman show that only intermediate-size innovations should be subsidized, while small and large-size innovations should be taxed, whereas Segerstrom basically finds that it is optimal to subsidize small-size innovations and to tax large-size innovations. Li (2003) and Sener (2008) generalize Segerstrom's analysis by taking into account the effect of "interindustry knowledge-spillover". The generalization of Sener confirms Segerstrom's results whereas Li shows that when interindustry knowledge-spillover effects are sufficiently large, R\&D subsidies should typically be subsidized. As a matter of fact, as stated by Sener (2008), "it is easy to find more papers in this literature with major differences in R\&D policy recommendations"; he adds that one can refer to Li (2003) or to Segerstrom (2007) "for a comparative analysis of R\&D policies implied by different endogenous growth models". As seen below in 3.3 .2 , our analysis enables us to identify a clear link between the intensity of knowledge spillovers and R\&D public policies.

${ }^{21}$ The proof of (20) is straightforward. Regarding the first equivalence, at each date $t$, one has, for all $\omega \in \Omega$, $\Pi_{\omega t}^{x}\left(\psi^{o}, 0\right)=\Pi_{t}^{x}\left(\psi^{o}, 0\right)=\frac{(1-\alpha) \alpha^{\frac{\alpha}{1-\alpha}}}{\lambda} \mathcal{K}_{t}\left(\psi^{o}, 0\right)$, where $\mathcal{K}_{t}\left(\psi^{o}, 0\right)=e^{g\left(\psi^{o}, 0\right) t}$ and $\mathcal{V}_{\omega t}^{o}=\mathcal{V}_{t}^{o}=\frac{(1-\alpha) \alpha^{\frac{\alpha}{1-\alpha}}}{\lambda} \mathcal{K}_{t}^{o}$, where $\mathcal{K}_{t}^{o}=e^{g^{o} t}$. One immediately gets $g\left(\psi^{o}, 0\right) \lesseqgtr g^{o} \Leftrightarrow \Pi_{\omega t}^{x}\left(\psi^{o}, 0\right) \lesseqgtr \mathcal{V}_{\omega t}^{o}$. Regarding the second equivalence, from Proposition 2 one has $g^{o}=\frac{\lambda \sigma \theta}{\gamma}-\rho$; and from Proposition 3 and its corollary, one gets $g\left(\psi^{o}, 0\right)=$ $\lambda \sigma \theta\left[\frac{1}{\gamma}-\left(\frac{\lambda}{\gamma}+\rho\right) / 2 \lambda\right]$. Therefore, one has $g\left(\psi^{o}, 0\right) \lesseqgtr g^{o} \Leftrightarrow \frac{\sigma \theta}{\rho}\left(\frac{\lambda}{\gamma}+\rho\right)-2=\varphi^{o} \gtreqless 0$. 


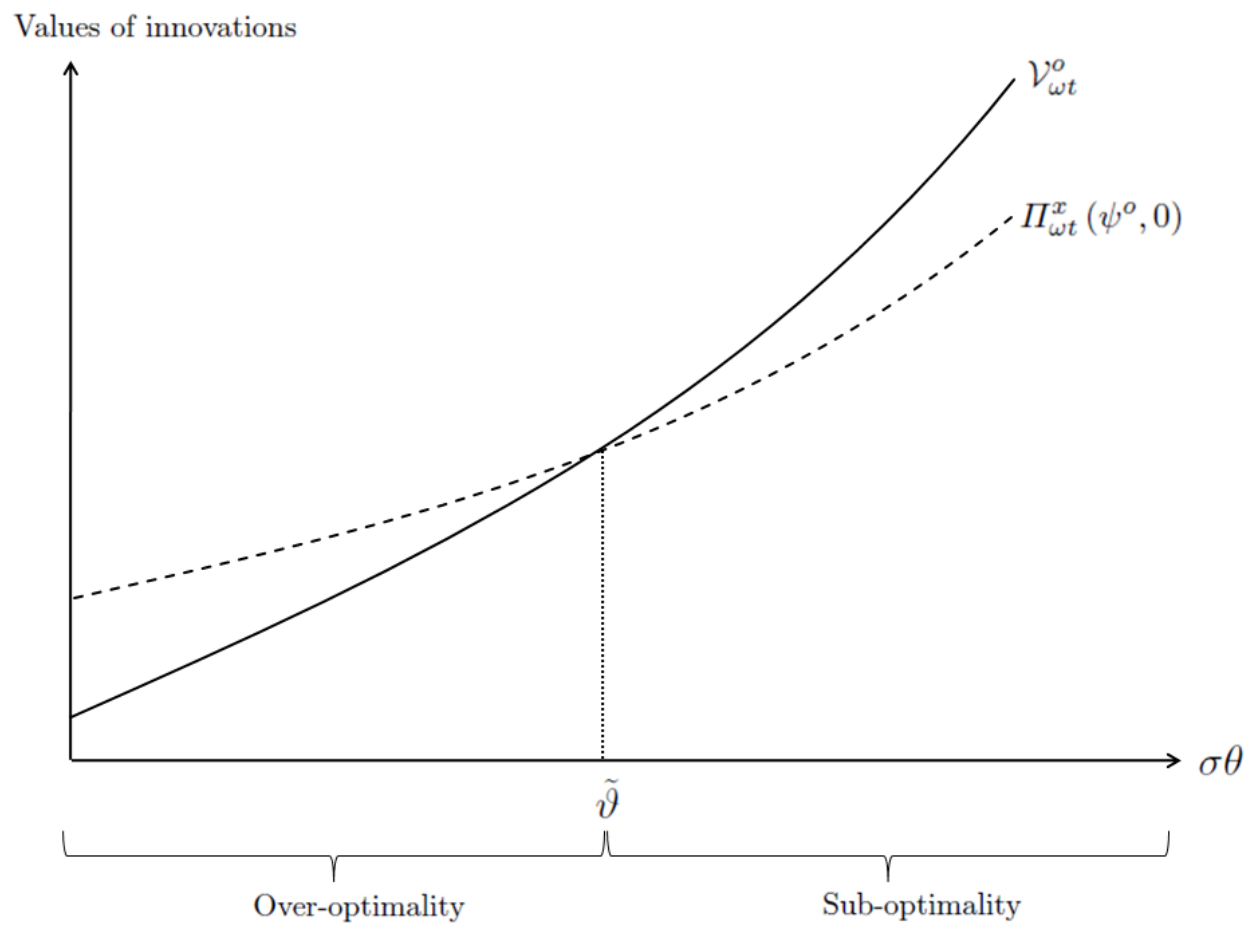

Figure 1: Social value versus private value of innovations: non-optimality revisited

point is that the private and the social values of innovations are at the heart of the design of R\&D incentives. In Figure 1, we illustrate the fact that these two values depend positively on $\sigma \theta$, but in a different way precisely because the Schumpeterian equilibrium exhibits incomplete markets. In fact, one can determine the threshold $\tilde{\vartheta} \equiv 2 \rho /(\lambda / \gamma+\rho)$ such that the private value of innovations is lower (resp. greater) than the social one if and only if $\sigma \theta$ is above (resp. below) this threshold. Formally, one has the following equivalence: ${ }^{22}$

$$
\Pi_{\omega t}^{x}\left(\psi^{o}, 0\right) \lesseqgtr \mathcal{V}_{\omega t}^{o} \Leftrightarrow \sigma \theta \gtreqless \tilde{\vartheta}, \forall \omega, \forall t
$$

If $\sigma \theta$ is large, it is likely that $\mathrm{R} \& \mathrm{D}$ investment will be insufficient, that is why $\mathrm{R} \& \mathrm{D}$ should be subsidized. Conversely, if $\sigma \theta$ is small, it is likely that R\&D investment will be excessive and thus that $\mathrm{R} \& \mathrm{D}$ should be taxed. In order to understand this result, let us return to the effects detailed above in 3.3.1. Recall that $v_{\omega t}^{R \& D o}$ (the sum of the Lindahl prices for all R\&D activities using knowledge $\chi_{\omega t}$ ) is increasing in $\sigma \theta$. Moreover, as argued above in point b), it is a key component of the social value of innovations that is absent from their private value. The larger $\sigma \theta$ is, the more significant the neglected value $v_{\omega t}^{R \& D o}$ is; hence the stronger the effect b) is; and finally the more likely the effect a) will be outweighed by the other effects (i.e. the appropriability effect and the two effects b) and c)). That is why one has $\Pi_{\omega t}^{x}\left(\psi^{o}, 0\right)<\mathcal{V}_{\omega t}^{o}$ when $\sigma \theta$ is sufficiently large. On the contrary, the smaller $\sigma \theta$ is, the weaker the effect b) is; and thus the more likely the effect a) will overcome the other effects. That is why one has $\Pi_{\omega t}^{x}\left(\psi^{o}, 0\right)>\mathcal{V}_{\omega t}^{o}$ for low values of $\sigma \theta$.

\section{Conclusion}

This paper arises from the observation that, traditionally, the social value of innovations is not explicitly determined in standard growth theory. Our main motivation was to compute it. For that purpose, we introduced the concept of Lindahl equilibrium in a Schumpeterian growth model: we completed markets by pricing knowledge and we computed the Lindahl prices. Admittedly, the Lindahl equilibrium is clearly a non realistic decentralized economy. However, beyond the academic interest, it also provides a benchmark allowing us to study several relevant issues related to innovations and R\&D incentives.

\footnotetext{
${ }^{22}$ The proof of this inequality follows immediately from the proof of (20).
} 
The comparison between the Lindahl equilibrium and the standard Schumpeterian one revealed the major part played by market incompleteness in the latter. It enabled us to shed a new light on the issue of Pareto non-optimality often debated in the literature. Furthermore, it allowed us to determine what should be the optimal R\&D incentives provided to each innovator in the presence of cumulative innovations, within a dynamic general equilibrium model with accumulation and diffusion of knowledge. Basically, each innovator should receive the social value of his innovation, which is derived owing to the Lindahl equilibrium.

Maybe the main interest of the Lindahl equilibrium lies in further research. One of the major features of the economy is most certainly its progressive dematerialization. Regarding R\&D activity, this means that new ideas - that is new knowledge - are more and more embodied into goods that are almost non rival. Many of these "knowledge-products" or "information goods" mentioned by Quah and Scotchmer are nowadays protected by IPRs; see, for instance, Chantrel, Grimaud \& Tournemaine 2012 for a survey on the evolution of intellectual property law. In other words, in the real economy, knowledge is already priced; markets for knowledge are thus already existing. The Lindahl equilibrium is a benchmark which can enable us to introduce realistic markets for knowledge in growth models.

\section{Appendix}

\subsection{Law of knowledge accumulation}

\subsubsection{Proof of Lemma 1}

Consider any given sector $\omega, \omega \in \Omega$, and a time interval $(t, t+\Delta t)$. The level of knowledge at date $t$ in this sector is $\chi_{\omega t}$. Let $k, k \in \mathbb{N}$, be the number of innovations that occur during the interval $(t, t+\Delta t)$.

Under Assumptions 1 and 2, the level of knowledge at date $t+\Delta t, \chi_{\omega t+\Delta t}$, is a random variable taking the values $\left\{\chi_{\omega t}+k \sigma \mathcal{P}_{\omega t}\right\}_{k \in \mathbb{N}}$ with associated probabilities $\left\{\frac{\left(\int_{t}^{t+\Delta t} \lambda l_{\omega u} d u\right)^{k}}{k !} e^{-\int_{t}^{t+\Delta t} \lambda l_{\omega u} d u}\right\}_{k \in \mathbb{N}}$. Accordingly, the expected level of knowledge at date $t+\Delta t$ is

$$
\begin{aligned}
& \mathbb{E}\left[\chi_{\omega t+\Delta t}\right]=\sum_{k=0}^{\infty} \frac{\left(\int_{t}^{t+\Delta t} \lambda l_{\omega u} d u\right)^{k}}{k !} e^{-\int_{t}^{t+\Delta t} \lambda l_{\omega u} d u}\left[\chi_{\omega t}+k \sigma \mathcal{P}_{\omega t}\right] \\
& =\left[\chi_{\omega t} \sum_{k=0}^{\infty} \frac{\left(\int_{t}^{t+\Delta t} \lambda l_{\omega u} d u\right)^{k}}{k !}+\sigma \mathcal{P}_{\omega t}\left(\int_{t}^{t+\Delta t} \lambda l_{\omega u} d u\right) \sum_{k=1}^{\infty} \frac{\left(\int_{t}^{t+\Delta t} \lambda l_{\omega u} d u\right)^{k-1}}{(k-1) !}\right] e^{-\int_{t}^{t+\Delta t} \lambda l_{\omega u} d u}
\end{aligned}
$$

The MacLaurin series $\sum_{k=0}^{K} \frac{\left(\int_{t}^{t+\Delta t} \lambda l_{\omega u} d u\right)^{k}}{k !}$ converges to $e^{\int_{t}^{t+\Delta t} \lambda l_{\omega u} d u}$ as $K \rightarrow \infty$. Thus, one gets

$$
\begin{gathered}
\mathbb{E}\left[\chi_{\omega t+\Delta t}\right]=\left[\chi_{\omega t} e^{\int_{t}^{t+\Delta t} \lambda l_{\omega u} d u}+\sigma \mathcal{P}_{\omega t}\left(\int_{t}^{t+\Delta t} \lambda l_{\omega u} d u\right) e^{\int_{t}^{t+\Delta t} \lambda l_{\omega u} d u}\right] e^{-\int_{t}^{t+\Delta t} \lambda l_{\omega u} d u} \\
\Leftrightarrow \mathbb{E}\left[\chi_{\omega t+\Delta t}\right]=\chi_{\omega t}+\lambda \sigma\left(\int_{t}^{t+\Delta t} l_{\omega u} d u\right) \mathcal{P}_{\omega t}
\end{gathered}
$$

Let $\Lambda_{\omega u}$ denote a primitive of $l_{\omega u}$ with respect to the time variable $u$. Rewriting the previous expression, one exhibits Newton's difference quotients of $\mathbb{E}\left[\chi_{\omega t}\right]$ and of $\Lambda_{\omega t}$ :

$$
\frac{\mathbb{E}\left[\chi_{\omega t+\Delta t}\right]-\chi_{\omega t}}{\Delta t}=\lambda \sigma \frac{\Lambda_{\omega t+\Delta t}-\Lambda_{\omega t}}{\Delta t} \mathcal{P}_{\omega t}
$$

Finally, letting $\Delta t$ tend to zero, one gets $\frac{\partial \mathbb{E}\left[\chi_{\omega t}\right]}{\partial t} \equiv \dot{\chi}_{\omega t}=\lambda \sigma l_{\omega t} \mathcal{P}_{\omega t}$. This proves that the expected knowledge in any sector $\omega$ is a differentiable function of time. Its derivative gives the law of motion of the expected knowledge as given in Lemma 1, in which the expectation operator is dropped to simplify notations. 


\subsubsection{Particular cases}

The law of motion derived in Lemma 1 is quite general. Indeed, choosing particular specifications of the pools $\mathcal{P}_{\omega t}$ enables us to obtain several laws of knowledge accumulation commonly used in the fully endogenous Schumpeterian growth theory. We propose to classify the various models proposed in this literature in four main ranges, according to the considered pools of knowledge (i.e. the considered types of knowledge spillovers).

No knowledge spillovers (neither inter nor intra-sectoral knowledge spillovers). In Barro \& Sala-i-Martin (2003 - Ch. 6) or in Peretto (2007), for instance, the knowledge production technology uses final good only. In this extreme case, there are neither inter-sectoral nor intrasectoral knowledge spillovers. A similar framework in which new knowledge is produced only with private inputs can also be considered using our formalization. Assume that $\mathcal{P}_{\omega t}=1$; accordingly, one has $\dot{\chi}_{\omega t}=\lambda \sigma l_{\omega t}, \forall \omega \in \Omega$. In this case, the only input used in the production of knowledge is labor.

Only intra-sectoral knowledge spillovers (no inter-sectoral knowledge spillovers). In the models proposed by Grossman \& Helpman (1991), Segerstrom (1998), Peretto (1999), Acemoglu (2009 - Ch. 14), or Aghion \& Howitt (2009 - Ch. 4), among others, it is implicitly assumed that spillovers are only intra-sectoral (there are no spillovers across sectors): the pool of knowledge used in each sector comprises only the knowledge previously accumulated within this sector. This type of model can be obtained assuming that $\mathcal{P}_{\omega t}=\chi_{\omega t}, \forall \omega \in \Omega$. One gets the following knowledge production functions $\dot{\chi}_{\omega t}=\lambda \sigma l_{\omega t} \chi_{\omega t}, \forall \omega \in \Omega$.

Knowledge spillovers depending on average knowledge. The models of Aghion \& Howitt (1998 - Ch. 12), Dinopoulos \& Thompson (1998), Peretto (1998), Li (2003), among others, consider firm-specific knowledge production functions such that, as stated by Laincz \& Peretto (2006), "spillovers depend on average knowledge". Surveying this literature, these authors formalize this assumption in equation (9) of their paper. One can equivalently refer to equations (7) and (9) in Jones (1999), to equations (13) and (14) in Dinopoulos \& Sener (2007), to equation (5) in Ha \& Howitt (2007), or to the framework used in Aghion \& Howitt (2009 - Ch. 4). Using our notations, this normalization assumption gives the following knowledge production function $\dot{\chi}_{\omega t}=\lambda \sigma l_{\omega t} \mathcal{P}_{\omega t}$, where $\mathcal{P}_{\omega t}=\int_{\Omega} \frac{\chi_{h t}}{N} d h, \forall \omega \in \Omega$. Here, the new knowledge produced in any given sector depends on a knowledge aggregator, which is the average knowledge within the whole economy. This formalization has been introduced to remove the scale effect property while maintaining the endogenous ingredients of the seminal literature. Note, however, that it appears that the cases in which knowledge spillovers are only intra-sectoral and those in which they depend on average knowledge are closely related. Indeed, in both of these frameworks, there are no inter-sectoral knowledge spillovers: since one generally considers the symmetric case in which $\chi_{\omega t}=\chi_{t}, \forall \omega \in \Omega$, one has $\mathcal{P}_{\omega t}=\frac{\chi_{t}}{N} \int_{\Omega} d h=\chi_{t}, \forall \omega \in \Omega$. Scale effects are canceled by removing inter-sectoral knowledge diffusion.

Knowledge spillovers depending on the knowledge level of the frontier firms ("leadingedge technology"). In the models of Aghion \& Howitt (1992), Young (1998), Howitt (1999), Segerstrom (2000), or Garner (2010), among others, the increase in knowledge consecutive to the occurrence of an innovation in any given sector at date $t$ depends on the level of knowledge reached in the most advanced sector. This type of framework can be directly obtained from our formalization. Indeed, assuming $\mathcal{P}_{\omega t}=\chi_{t}^{\max }$, where $\chi_{t}^{\max } \equiv \max \left\{\chi_{\omega t}, \omega \in \Omega\right\}$, one gets $\dot{\chi}_{\omega t}=\lambda \sigma l_{\omega t} \chi_{t}^{\max }, \forall \omega \in \Omega$.

Global knowledge spillovers. A last range of models assumes that knowledge spillovers are global: each sector uses the whole disposable knowledge in the economy, that is $\mathcal{P}_{\omega t}=\int_{\Omega} \chi_{h t} d h=$ $\mathcal{K}_{t}$. Accordingly, one gets the following knowledge production function:

$$
\dot{\chi}_{\omega t}=\lambda \sigma l_{\omega t} \mathcal{K}_{t}, \forall \omega \in \Omega
$$

Comments on the law of knowledge accumulation (22) are given in Section 2 (see 2.1.2). In particular, we show how it relates to the ones originally introduced in the seminal papers of Romer (1990) and of Aghion \& Howitt (1992). See the comments of the corollary to Proposition 1. 


\subsection{First-best social optimum - Proof of Proposition 2}

The social planner maximizes the representative household's discounted utility (3) subject to (1), (2), (4), (5), (6) and (7). The maximization program can be written as follows:

$$
\begin{aligned}
& \operatorname{Max} \mathcal{U}=\int_{0}^{\infty} \ln \left(c_{t}\right) e^{-\rho t} d t \text { subject to } \\
& \left\{c_{t}\right\}_{t \in[0, \infty[} \\
& \left\{L_{t}^{Y}\right\}_{t \in[0, \infty[} \\
& \left\{l_{\omega t}\right\}_{t \in[0, \infty[, \omega \in \Omega} \\
& \left\{x_{\omega t}\right\}_{t \in[0, \infty[, \omega \in \Omega}
\end{aligned} \quad\left\{\begin{array}{l}
\mathcal{K}_{t}=\int_{\Omega} \chi_{\omega t} d \omega \\
\dot{\chi}_{\omega t}=\lambda \sigma l_{\omega t} \mathcal{P}_{\omega t}, \omega \in \Omega \\
\mathcal{P}_{\omega t}=\int_{\Omega_{\omega}} \chi_{h t} d h, \forall \omega \in \Omega \\
L=L_{t}^{Y}+\int_{\Omega} l_{\omega t} d \omega \\
Y_{t}=\left(L_{t}^{Y}\right)^{1-\alpha} \int_{\Omega} \chi_{\omega t}\left(x_{\omega t}\right)^{\alpha} d \omega \\
x_{\omega t}=\frac{y_{\omega t}}{\chi_{\omega t}}, \omega \in \Omega \\
Y_{t}=L c_{t}+\int_{\Omega} y_{\omega t} d \omega
\end{array}\right.
$$

where $c_{t}, L_{t}^{Y}, l_{\omega t}$ and $x_{\omega t}, \omega \in \Omega$, are the control variables, and $\chi_{\omega t}, \omega \in \Omega$, the continuum of state variables of the dynamic optimization problem. ${ }^{23}$ We denote by $\iota_{\omega t}, \omega \in \Omega, \nu_{t}$ and $\mu_{t}$, the co-state variables associated with the continuum of state variables, to the labor constraint, and to the final good resource constraint, respectively. After some rearrangement, one can write the Hamiltonian as:

$$
\begin{aligned}
\mathcal{H}=\ln \left(c_{t}\right) e^{-\rho t}+\mu_{t}\left[\left(L_{t}^{Y}\right)^{1-\alpha} \int_{\Omega} \chi_{\omega t}\left(x_{\omega t}\right)^{\alpha} d \omega-L c_{t}-\int_{\Omega} \chi_{\omega t} x_{\omega t} d \omega\right] \\
+\nu_{t}\left[L-L_{t}^{Y}-\int_{\Omega} l_{\omega t} d \omega\right]+\int_{\Omega} \iota_{\omega t}\left[\lambda \sigma l_{\omega t} \int_{\Omega_{\omega}} \chi_{h t} d h\right] d \omega
\end{aligned}
$$

The first-order conditions $\frac{\partial \mathcal{H}}{\partial c_{t}}=0, \frac{\partial \mathcal{H}}{\partial L_{t}^{Y}}=0, \frac{\partial \mathcal{H}}{\partial l_{i t}}=0(i \in \Omega), \frac{\partial \mathcal{H}}{\partial x_{i t}}=0(i \in \Omega)$ and $\frac{\partial \mathcal{H}}{\partial \chi_{i t}}=-\iota_{i t}(i \in$ $\Omega)$ respectively yield: ${ }^{24}$

$$
\begin{gathered}
c_{t}^{-1} e^{-\rho t}=\mu_{t} L \\
\mu_{t}(1-\alpha) \frac{Y_{t}}{L_{t}^{Y}}=\nu_{t} \\
\iota_{i t} \lambda \sigma \int_{\Omega_{\omega}} \chi_{h t} d h=\nu_{t}, \forall i \in \Omega \\
\mu_{t}\left[\alpha\left(L_{t}^{Y}\right)^{1-\alpha} \chi_{i t}\left(x_{i t}\right)^{\alpha-1}-\chi_{i t}\right]=0, \forall i \in \Omega \\
\mu_{t}\left[\left(L_{t}^{Y}\right)^{1-\alpha}\left(x_{i t}\right)^{\alpha}-x_{i t}\right]+\lambda \sigma \int_{\Omega_{i}} \iota_{h t} l_{h t} d h=-\iota_{i t}, \forall i \in \Omega
\end{gathered}
$$

From (26), one gets:

$$
x_{i t}=x_{t}=\alpha^{\frac{1}{1-\alpha}} L_{t}^{Y}, \forall i \in \Omega
$$

Plugging (28) in (5), and using the definition of the whole disposable knowledge in the economy (given by (1)), one gets:

$$
Y_{t}=\alpha^{\frac{\alpha}{1-\alpha}} L_{t}^{Y} \mathcal{K}_{t} \text { and thus } g_{Y_{t}}=g_{L_{t}^{Y}}+g_{\mathcal{K}_{t}}
$$

Moreover, plugging (28) in the final good resource constraint, (7) becomes $Y_{t}=L c_{t}+\alpha^{\frac{1}{1-\alpha}} L_{t}^{Y} \mathcal{K}_{t}$. Dividing both sides of this expression by $Y_{t}$ and using the previous expressions of $x_{t}$ and $Y_{t}$ (respectively given in (28) and (29)), one obtains $L c_{t} / Y_{t}=1-\alpha$; this gives

$$
g_{c_{t}}=g_{Y_{t}}
$$

Finally, the first-order conditions (24) and (27) become, respectively

$$
\begin{aligned}
& \mu_{t}(1-\alpha) \alpha^{\frac{\alpha}{1-\alpha}} \mathcal{K}_{t}=\nu_{t} \\
& \quad \text { and } \frac{\mu_{t}}{\iota_{i t}}(1-\alpha) \alpha^{\frac{\alpha}{1-\alpha}} L_{t}^{Y}+\lambda \sigma \int_{\Omega_{i}} \frac{\iota_{h t}}{\iota_{i t}} l_{h t} d h=-g_{\iota i t}, \forall i \in \Omega
\end{aligned}
$$

\footnotetext{
${ }^{23}$ Accordingly, note that the constraint relative to the law of motion of knowledge is in fact a continuum of constraints.

${ }^{24}$ Plus the usual transversality conditions.
} 
We now consider the usual symmetric case in which $l_{\omega t}=l_{t}$ and $\chi_{\omega t}=\chi_{t} \forall \omega \in \Omega$. Accordingly, one has $\mathcal{P}_{\omega t}=\mathcal{P}_{t}=\theta \chi_{t}, \forall \omega \in \Omega$, and thus the following expression of the growth rate of the stocks of knowledge:

$$
g_{\mathcal{K}_{t}}=g_{\chi_{t}}=\frac{\dot{\chi_{t}}}{\chi_{t}}=\lambda \sigma \theta l_{t}
$$

Moreover, (25) becomes $\iota_{i t} \lambda \sigma \theta \mathcal{K}_{t} / N=\nu_{t}, \forall i \in \Omega$. Hence, one has $\iota_{i t}=\iota_{t}, \forall i \in \Omega$. Using (31) and the labor resource constraint, one gets $\frac{\mu_{t}}{\iota_{t}}=\frac{\lambda \sigma \theta}{(1-\alpha)^{\frac{\alpha}{1-\alpha}} N}$ and thus

$$
g_{\mu_{t}}=g_{\iota_{t}}=-\left(\frac{\lambda \sigma \theta L_{t}^{Y}}{N}+\lambda \sigma \theta l_{t}\right)=-\frac{\lambda \sigma \theta L}{N}=-\frac{\lambda \sigma \theta}{\gamma}
$$

Furthermore, the labor constraint (4) is now

$$
L_{t}^{Y}+N l_{t}=L \Leftrightarrow L_{t}^{Y}+\gamma L l_{t}=L \Leftrightarrow l_{t}=\frac{1}{\gamma}\left(1-\frac{L_{t}^{Y}}{L}\right)
$$

Finally, log-differentiating (23) gives $g_{c_{t}}+\rho=-g_{\mu_{t}}$; using (33) allows us to derive the optimal growth rate of per-capita consumption:

$$
g_{c}^{o}=\frac{\lambda \sigma \theta}{\gamma}-\rho
$$

The social optimum is completely characterized by (28), (29), (30), (32), (34) and (35); and therefore by the following system of equations (the superscript "o" is used for "social optimum"):

$$
\left\{\begin{array}{l}
g_{c}^{o}=\frac{\lambda \sigma \theta}{\gamma}-\rho \\
g_{c_{t}}^{o}=g_{Y_{t}}^{o}=g_{L_{t}}^{o}+g_{\mathcal{K}_{t}}^{o}=g_{L_{t}^{Y}}^{o}+\lambda \sigma \theta l_{t}^{o} \\
l_{t}^{o}=\frac{1}{\gamma}\left(1-L_{t}^{Y o} / L\right) \\
x_{t}^{o}=\alpha^{\frac{1}{1-\alpha}} L_{t}^{Y o}
\end{array}\right.
$$

From $(l 1),(l 2)$ and $(l 3)$ one gets

$$
\frac{\lambda \sigma \theta}{\gamma}-\rho=g_{L_{t}^{Y}}^{o}+\lambda \sigma \theta l_{t}^{o} \Leftrightarrow g_{L_{t}^{Y}}^{o}=\frac{\lambda \sigma \theta L_{t}^{Y o}}{\gamma L}-\rho
$$

In order to solve for $L_{t}^{Y o}$, we use a variable substitution. Let $X_{t}=1 / L_{t}^{Y o}$; one gets the first-order linear differential equation $\dot{X}_{t}-\rho X_{t}=-\lambda \sigma \theta / N$. Its solution is

$$
X_{t}=\left(X_{0}-\frac{\lambda \sigma \theta}{\rho N}\right) e^{\rho t}+\frac{\lambda \sigma \theta}{\rho N} \Leftrightarrow L_{t}^{Y o}=\frac{1}{\left(\frac{1}{L_{0}^{Y o}}-\frac{\lambda \sigma \theta}{\rho N}\right) e^{\rho t}+\frac{\lambda \sigma \theta}{\rho N}}
$$

Using the transversality condition, it can be shown that $L_{t}^{Y o}$ immediately jumps to its steadystate level $L^{Y o^{s s}}=\rho N / \lambda \sigma \theta$. The transversality condition is only satisfied when $L_{t}^{Y o}=L^{Y o^{s s}}, \forall t$. Thus, one has $g_{L_{t}^{Y}}^{o}=0$.

Finally, replacing $L_{t}^{Y o}$ in the system of equations (36) and using the assumption $N=\gamma L$, one obtains the characterization of the social optimum as exhibited in Proposition 2.

\subsection{Schumpeterian equilibrium à la Aghion \& Howitt (1992) and private value of innovations - Proof of Propositions 3 and 4}

In this subsection, we provide the detailed analysis of a decentralized economy à la Aghion \& Howitt (1992), we fully characterize the set of equilibria as functions of the public tools vector $(\psi, \varphi)$ and we compute the private value of innovations. As stated in Definition 2, at each vector $(\psi, \varphi)$ is associated a particular Schumpeterian equilibrium, which consists of time paths of set of prices

and of quantities

$$
\left\{\left(w_{t}(\psi, \varphi), r_{t}(\psi, \varphi),\left\{q_{\omega t}(\psi, \varphi)\right\}_{\omega \in \Omega}\right)\right\}_{t=0}^{\infty}
$$

$$
\left\{\left(c_{t}(\psi, \varphi), Y_{t}(\psi, \varphi),\left\{x_{\omega t}(\psi, \varphi)\right\}_{\omega \in \Omega}, L_{t}^{Y}(\psi, \varphi),\left\{l_{\omega t}(\psi, \varphi)\right\}_{\omega \in \Omega},\left\{\chi_{\omega t}(\psi, \varphi)\right\}_{\omega \in \Omega}\right)\right\}_{t=0}^{\infty}
$$


such that: the representative household maximizes his utility; firms maximize their profits; the final good market, the financial market and the labor market are perfectly competitive and clear; on each intermediate good market, the innovator is granted an infinitely-lived patent and monopolizes the production and sale until replaced by the next innovator; and there is free entry on each R\&D activity. For all the computations, in order to simplify notations, we drop the $(\psi, \varphi)$ arguments for all variables.

The representative household maximizes his intertemporal utility given by (3) subject to his budget constraint, $\dot{b}_{t}=w_{t}+r_{t} b_{t}-c_{t}-T_{t} / L$, where $b_{t}$ denotes the per capita financial asset and $T_{t}$ is a lump-sum tax charged by the government in order to finance public policies. This yields the usual Keynes-Ramsey condition:

$$
r_{t}=g_{c_{t}}+\rho
$$

In the final sector, the competitive firm maximizes its profit given by $\pi_{t}^{Y}=\left(L_{t}^{Y}\right)^{1-\alpha} \int_{\Omega} \chi_{\omega t}\left(x_{\omega t}\right)^{\alpha} d \omega-$ $w_{t} L_{t}^{Y}-\int_{\Omega}(1-\psi) q_{\omega t} x_{\omega t} d \omega$. The first-order conditions yield

$$
w_{t}=(1-\alpha) \frac{Y_{t}}{L_{t}^{Y}} \quad \text { and } \quad q_{\omega t}=\frac{\alpha\left(L_{t}^{Y}\right)^{1-\alpha} \chi_{\omega t}\left(x_{\omega t}\right)^{\alpha-1}}{1-\psi}, \forall \omega \in \Omega
$$

Consider any sector $\omega, \omega \in \Omega$. Given the governmental intervention on behalf of R\&D activities, the incumbent innovator, having successfully innovated at date $t$, receives at any date $\tau>t$ the net profit $\pi_{\tau}^{x_{\omega}}=(1+\varphi)\left(q_{\omega t} x_{\omega t}-y_{\omega t}\right)$ with probability $e^{-\int_{t}^{\tau} \lambda l_{\omega u} d u}$. Differentiating (9) with respect to time gives the standard arbitrage condition in each R\&D activity $\omega$ :

$$
r_{t}+\lambda l_{\omega t}=\frac{\dot{\Pi}_{\omega t}^{x}}{\Pi_{\omega t}^{x}}+\frac{\pi_{t}^{x_{\omega}}}{\Pi_{\omega t}^{x}}, \forall \omega \in \Omega
$$

In what follows, we focus on the case of unconstrained monopoly, that is, the case of drastic innovations. As shown below in the remark (see (57)), innovations are drastic if and only if $\sigma \theta>1 / \alpha^{\frac{\alpha}{1-\alpha}}-1$. In each intermediate good sector $\omega, \omega \in \Omega$, the incumbent monopoly maximizes the instantaneous net profit $\pi_{t}^{x_{\omega}}$, where the demand for intermediate good $\omega, x_{\omega t}$, is given by (38) and the quantity of final good used in the production is $y_{\omega t}=x_{\omega t} \chi_{\omega t}$ (see (6)). Maximization gives the usual symmetric use of intermediate goods in the final good production and the usual mark-up on the price of intermediate goods:

$$
x_{\omega t}=x_{t}=\left(\frac{\alpha^{2}}{1-\psi}\right)^{\frac{1}{1-\alpha}} L_{t}^{Y} \text { and } q_{\omega t}=\frac{\chi_{\omega t}}{\alpha}, \forall \omega \in \Omega
$$

The monopoly profits now write:

$$
\begin{aligned}
\pi_{\tau}^{x_{\omega}}=(1+\varphi)\left(q_{\omega t} x_{\omega t}-y_{\omega t}\right)=(1+\varphi) & \left(\frac{1-\alpha}{\alpha}\right) \chi_{\omega t} x_{\omega t} \\
& =(1+\varphi)\left(\frac{1-\alpha}{\alpha}\right) \chi_{\omega t}\left(\frac{\alpha^{2}}{1-\psi}\right)^{\frac{1}{1-\alpha}} L_{t}^{Y}, \forall \omega \in \Omega
\end{aligned}
$$

Together with the definition of the whole disposable knowledge in the economy (1), (40) allows us to rewrite the final good production function (5) and the wage expression given in (38), respectively, as

$$
Y_{t}=\left(\frac{\alpha^{2}}{1-\psi}\right)^{\frac{\alpha}{1-\alpha}} L_{t}^{Y} \mathcal{K}_{t} \text { and } w_{t}=(1-\alpha)\left(\frac{\alpha^{2}}{1-\psi}\right)^{\frac{\alpha}{1-\alpha}} \mathcal{K}_{t}
$$

The free entry condition condition in any R\&D activity $\omega$ is $w_{t}=\lambda \Pi_{\omega t}^{x}$, where $\lambda \Pi_{\omega t}^{x}$ is the expected revenue when one unit of labor is invested in R\&D (from Assumption 1), and $w_{t}$ is the cost of one unit of labor (given in (42)). This condition gives the private value of an innovation in sector $\omega$ at date $t$, as defined in (9):

$$
\Pi_{\omega t}^{x}=\Pi_{t}^{x}=\frac{(1-\alpha)}{\lambda}\left(\frac{\alpha^{2}}{1-\psi}\right)^{\frac{\alpha}{1-\alpha}} \mathcal{K}_{t}, \forall \omega \in \Omega
$$

Consequently, one has $\dot{\Pi}_{\omega t}^{x} / \Pi_{\omega t}^{x}=g_{\mathcal{K}_{t}}$. Moreover, using (41) and (43), one gets

$$
\frac{\pi_{t}^{x_{\omega}}}{\Pi_{\omega t}^{x}}=\frac{(1+\varphi)\left(\frac{1-\alpha}{\alpha}\right) \chi_{\omega t}\left(\frac{\alpha^{2}}{1-\psi}\right)^{\frac{1}{1-\alpha}} L_{t}^{Y}}{\frac{(1-\alpha)}{\lambda}\left(\frac{\alpha^{2}}{1-\psi}\right)^{\frac{\alpha}{1-\alpha}} \mathcal{K}_{t}}=\frac{(1+\varphi) \lambda \alpha \chi_{\omega t} L_{t}^{Y}}{(1-\psi) \mathcal{K}_{t}}, \forall \omega \in \Omega
$$


The arbitrage condition (39) now writes

$$
r_{t}+\lambda l_{\omega t}=g_{\mathcal{K}_{t}}+\frac{(1+\varphi) \lambda \alpha L_{t}^{Y} \chi_{\omega t}}{(1-\psi) \mathcal{K}_{t}}, \forall \omega \in \Omega
$$

Log-differentiating with respect to time the expression of the final good production function given in (42) gives

$$
g_{Y_{t}}=g_{L_{t}^{Y}}+g_{\mathcal{K}_{t}}
$$

Furthermore, using (1), (6) and (40), the final good resource constraint (7) can be rewritten as $Y_{t}=L c_{t}+\left[\alpha^{2} /(1-\psi)\right]^{\frac{1}{1-\alpha}} L_{t}^{Y} \mathcal{K}_{t}$. Dividing both sides by $Y_{t}$ and using the expression of $Y_{t}$ given in (42), one gets $L c_{t} / Y_{t}=1-\alpha^{2} /(1-\psi)$. Log-differentiating this expression gives

$$
g_{Y_{t}}=g_{c_{t}}
$$

As usually in the standard literature, we focus on the symmetric equilibrium, in which $l_{\omega t}=l_{t}$ and $\chi_{\omega t}=\chi_{t}, \forall \omega \in \Omega$. Consequently, one has $\mathcal{K}_{t}=N \chi_{t}$. Hence, the growth rate of the whole disposable knowledge is $g_{\mathcal{K}_{t}}=g_{\chi_{t}}$. Moreover, the pools of knowledge and the laws of accumulation of knowledge in each sector $\omega$ are respectively given by $\mathcal{P}_{\omega t}=\mathcal{P}_{t}=\theta \chi_{t}$ and $\dot{\chi}_{\omega t}=\dot{\chi}_{t}=\lambda \sigma \theta l_{t} \chi_{t}$, $\forall \omega \in \Omega$. Therefore, one has

$$
g_{\chi_{\omega t}}=g_{\chi_{t}}=g_{\mathcal{K}_{t}}=\lambda \sigma \theta l_{t}, \forall \omega \in \Omega
$$

Finally, one can rewrite (45) - the arbitrage condition in any $R \& D$ activity $\omega, \omega \in \Omega$ - as follows:

$$
r_{t}+\lambda l_{t}=\lambda \sigma \theta l_{t}+\frac{(1+\varphi) \lambda \alpha L_{t}^{Y}}{(1-\psi) N}
$$

The equilibrium quantities, growth rates and prices are characterized by equations (4), (37), (40), (42), (46), (47), (48) and (49):

$$
\left\{\begin{array}{l}
L_{t}=L_{t}^{Y}+N l_{t} \\
r_{t}=g_{c_{t}}+\rho \\
x_{\omega t}=x_{t}=\left(\frac{\alpha^{2}}{1-\psi}\right)^{\frac{1}{1-\alpha}} L_{t}^{Y} \quad \text { and } \quad q_{\omega t}=\frac{\chi_{\omega t}}{\alpha}, \forall \omega \in \Omega_{t} \\
Y_{t}=\left(\frac{\alpha^{2}}{1-\psi}\right)^{\frac{\alpha}{1-\alpha}} L_{t}^{Y} \mathcal{K}_{t} \text { and } w_{t}=(1-\alpha)\left(\frac{\alpha^{2}}{1-\psi}\right)^{\frac{\alpha}{1-\alpha}} \mathcal{K}_{t} \\
g_{Y_{t}}=g_{L_{t}^{Y}}+g_{\mathcal{K}_{t}} \\
g_{Y_{t}}=g_{c_{t}} \\
g_{\chi_{\omega t}}=g_{\chi_{t}}=g_{\mathcal{K}_{t}}=\lambda \sigma \theta l_{t}, \forall \omega \in \Omega \\
r_{t}+\lambda l_{t}=\lambda \sigma \theta l_{t}+\frac{(1+\varphi) \lambda \alpha L_{t}^{Y}}{(1-\psi) N}
\end{array}\right.
$$

From (37) and (49), one gets $g_{c_{t}}+\rho+\lambda l_{t}=\lambda \sigma \theta l_{t}+\frac{(1+\varphi) \lambda \alpha L_{t}^{Y}}{(1-\psi) N}$. From (46), (47) and (48), one gets $g_{c_{t}}=g_{Y_{t}}=g_{L_{t}^{Y}}+g_{\chi_{t}}=g_{L_{t}^{Y}}+\lambda \sigma \theta l_{t}$. Using the labor constraint (4) and the assumption $N=\gamma L$ together with these two expressions, one gets the following differential equation in $L_{t}^{Y}$.

$$
g_{L_{t}^{Y}}-\frac{\lambda}{\gamma L}\left[1+\frac{1+\varphi}{1-\psi} \alpha\right] L_{t}^{Y}=-\left(\frac{\lambda}{\gamma}+\rho\right)
$$

We use the variable substitution $X_{t}=1 / L_{t}^{Y}$. Log-differentiation with respect to time writes $g_{X_{t}}=-g_{L_{t}^{Y}}$. Substituting into (51) gives

$$
\begin{array}{r}
-g_{X_{t}}-\frac{\lambda}{\gamma L}\left[1+\frac{1+\varphi}{1-\psi} \alpha\right] \frac{1}{X_{t}}=-\left(\frac{\lambda}{\gamma}+\rho\right) \\
\quad \Leftrightarrow \dot{X}_{t}-\left(\frac{\lambda}{\gamma}+\rho\right) X_{t}=-\frac{\lambda}{\gamma L}\left[1+\frac{1+\varphi}{1-\psi} \alpha\right]
\end{array}
$$

The solution of this first-order linear differential equation is

$$
X_{t}=e^{\left(\frac{\lambda}{\gamma}+\rho\right) t}\left(X_{0}-\frac{1}{\frac{\lambda}{\gamma}+\rho} \frac{\lambda}{\gamma L}\left[1+\frac{1+\varphi}{1-\psi} \alpha\right]\right)+\frac{1}{\frac{\lambda}{\gamma}+\rho} \frac{\lambda}{\gamma L}\left[1+\frac{1+\varphi}{1-\psi} \alpha\right]
$$


Accordingly, one obtains

$$
L_{t}^{Y}=\frac{1}{e^{\left(\frac{\lambda}{\gamma}+\rho\right) t}\left(\frac{1}{L_{0}^{Y}}-\frac{1}{\frac{\lambda}{\gamma}+\rho} \frac{\lambda}{\gamma L}\left[1+\frac{1+\varphi}{1-\psi} \alpha\right]\right)+\frac{1}{\frac{\lambda}{\gamma}+\rho} \frac{\lambda}{\gamma L}\left[1+\frac{1+\varphi}{1-\psi} \alpha\right]}
$$

Using the transversality condition in the program of the representative household, we can show that $L_{t}^{Y}$ immediately jumps to its steady-state level $L^{Y^{s s}}=\left(\frac{\lambda}{\gamma}+\rho\right) /\left(\frac{\lambda}{\gamma L}\left[1+\frac{1+\varphi}{1-\psi} \alpha\right]\right)$. The transversality condition is only satisfied when $L_{t}^{Y}=L_{0}^{Y}=\gamma L\left(\frac{\lambda}{\gamma}+\rho\right) /\left(\lambda\left[1+\frac{1+\varphi}{1-\psi} \alpha\right]\right), \forall t$. Thus, one has $g_{L_{t}^{Y}}=0$.

Substituting into the system (50), one proves Propositions 3 and 4, in which we provide the complete characterization of the decentralized Schumpeterian equilibrium and the private value of an innovation, respectively.

\section{Remark: drastic versus nondrastic innovations}

In the final sector, the competitive firm cost minimization program is

$$
\begin{aligned}
& \operatorname{Min} \mathcal{C}=w_{t} L_{t}^{Y}+\int_{\Omega}(1-\psi) q_{\omega t} x_{\omega t} d \omega \text { subject to } Y_{t}=\left(L_{t}^{Y}\right)^{1-\alpha} \int_{\Omega} \chi_{\omega t}\left(x_{\omega t}\right)^{\alpha} d \omega \\
& \left\{L_{t}^{Y}\right\},\left\{x_{\omega t}\right\}_{\omega \in \Omega}
\end{aligned}
$$

The first-order conditions with respect to $L_{t}^{Y}$ and $x_{\omega t}$ give respectively:

$$
\begin{gathered}
L_{t}^{Y}=\frac{\eta(1-\alpha) Y_{t}}{w_{t}} \\
\text { and }(1-\psi) q_{\omega t}=\eta \alpha\left(L_{t}^{Y}\right)^{1-\alpha} \chi_{\omega t}\left(x_{\omega t}\right)^{\alpha-1}, \forall \omega \in \Omega
\end{gathered}
$$

Furthermore, in the symmetric case, one has

$$
Y_{t}=\left(L_{t}^{Y}\right)^{1-\alpha} N \chi_{t}\left(x_{t}\right)^{\alpha}
$$

Then, (53) writes

$$
x_{t}=\frac{\eta \alpha\left(L_{t}^{Y}\right)^{1-\alpha} N \chi_{t}\left(x_{t}\right)^{\alpha}}{N(1-\psi) q_{t}}=\frac{\eta \alpha Y_{t}}{N(1-\psi) q_{t}}
$$

From (52) and (55), one gets $L_{t}^{Y} / x_{t}=(1-\alpha) N(1-\psi) q_{t} / \alpha w_{t}$; together with (54) one gets the following expressions of $L_{t}^{Y}$ and $x_{t}$ :

$$
L_{t}^{Y}=\frac{Y_{t}}{N \chi_{t}}\left(\frac{(1-\alpha) N(1-\psi) q_{t}}{\alpha w_{t}}\right)^{\alpha} \text { and } x_{t}=\frac{Y_{t}}{N \chi_{t}}\left(\frac{(1-\alpha) N(1-\psi) q_{t}}{\alpha w_{t}}\right)^{\alpha-1}
$$

Plugging in the total cost, $\mathcal{C}=w_{t} L_{t}^{Y}+\int_{\Omega}(1-\psi) q_{\omega t} x_{\omega t} d \omega$, one gets $\mathcal{C}=\frac{Y_{t}}{N \chi_{t}}\left[\frac{(1-\alpha) N}{\alpha}\right]^{\alpha}\left[(1-\psi) q_{t}\right]^{\alpha}\left(w_{t}\right)^{1-\alpha}+$ $N(1-\psi) q_{t} \frac{Y_{t}}{N \chi_{t}}\left[\frac{(1-\alpha) N(1-\psi) q_{t}}{\alpha w_{t}}\right]^{\alpha-1}$. Finally, the cost function of the final sector is

$$
\mathcal{C}\left(Y_{t}, \chi_{t}, q_{t}, w_{t}\right)=\frac{N^{\alpha-1}}{1-\alpha}\left(\frac{1-\alpha}{\alpha}\right)^{\alpha} \frac{Y_{t}}{\chi_{t}}\left[(1-\psi) q_{t}\right]^{\alpha}\left(w_{t}\right)^{1-\alpha}
$$

Consider any given sector $\omega, \omega \in \Omega$. If an innovation occurs at date $t$, the quality reached by its producer (i.e. the new level of knowledge in this sector attained by the latest innovator) is $\chi_{\omega t}+\Delta \chi_{\omega t}=\chi_{\omega t}+\sigma \mathcal{P}_{\omega t}$, where $\chi_{\omega t}$ is the quality reached by the previous innovator (i.e. the level of knowledge achieved through the previous innovations in this sector). In the symmetric case, one has $\chi_{\omega t}=\chi_{t}$, and thus $\mathcal{P}_{\omega t}=\theta \chi_{t}, \forall \omega \in \Omega$; then, the quality attained by the latest innovator writes $(1+\sigma \theta) \chi_{t}$. The final sector can buy the intermediate good from the latest innovator at the marked-up price $q_{t}=\frac{(1+\sigma \theta) \chi_{t}}{\alpha}$, or from the previous innovator at the competitive price $q_{t}=\chi_{t}$. In the former case, the cost function is $\mathcal{C}\left(Y_{t},(1+\sigma \theta) \chi_{t}, q_{t}=\frac{(1+\sigma \theta) \chi_{t}}{\alpha}, w_{t}\right)$; in the latter case, it 
is $\mathcal{C}\left(Y_{t}, \chi_{t}, q_{t}=\chi_{t}, w_{t}\right)$. The innovation is drastic if and only if

$$
\begin{gathered}
\mathcal{C}\left(Y_{t},(1+\sigma \theta) \chi_{t}, q_{t}=\frac{(1+\sigma \theta) \chi_{t}}{\alpha}, w_{t}\right)<\mathcal{C}\left(Y_{t}, \chi_{t}, q_{t}=\chi_{t}, w_{t}\right) \\
\Leftrightarrow \frac{N^{\alpha-1}}{1-\alpha}\left(\frac{1-\alpha}{\alpha}\right)^{\alpha} \frac{Y_{t}}{(1+\sigma \theta) \chi_{t}}\left[(1-\psi) \frac{(1+\sigma \theta) \chi_{t}}{\alpha}\right]^{\alpha}\left(w_{t}\right)^{1-\alpha} \\
\quad<\frac{N^{\alpha-1}}{1-\alpha}\left(\frac{1-\alpha}{\alpha}\right)^{\alpha} \frac{Y_{t}}{\chi_{t}}\left[(1-\psi) \chi_{t}\right]^{\alpha}\left(w_{t}\right)^{1-\alpha} \\
\Leftrightarrow \sigma \theta>\frac{1}{\alpha^{\frac{\alpha}{1-\alpha}}-1}
\end{gathered}
$$

\subsection{Lindahl equilibrium and social value of innovations - Proof of Propo- sitions 5 and 6}

The representative household maximizes his intertemporal utility given by (3) subject to his budget constraint, $\dot{b}_{t}=w_{t}+r_{t} b_{t}-c_{t}-T_{t} / L$, where $b_{t}$ denotes the per capita financial asset and $T_{t}$ is a lump-sum tax charged by the government in order to finance public policies and fund R\&D expenditures. This yields the usual Keynes-Ramsey condition:

$$
r_{t}=g_{c_{t}}+\rho
$$

Differentiating (11) with respect to time gives an arbitrage condition stating that the rate of return is the same on the financial market and on any $R \& D$ investment:

$$
r_{t}=\frac{v_{\omega t}}{V_{\omega t}}+\frac{\dot{V}_{\omega t}}{V_{\omega t}}, \forall \omega \in \Omega
$$

As usual in the standard literature, we focus on a symmetric equilibrium in which $l_{\omega t}=l_{t}$ and $\chi_{\omega t}=\chi_{t}, \forall \omega \in \Omega$. Consequently, since $N=\gamma L$, one has $\mathcal{K}_{t}=N \chi_{t}=\gamma L \chi_{t}$ and $L=L_{t}^{Y}+\gamma L l_{t}$. The pools of knowledge and the laws of accumulation of knowledge in each sector $\omega$ are now respectively given by $\mathcal{P}_{\omega t}=\mathcal{P}_{t}=\theta \chi_{t}$ and $\dot{\chi}_{\omega t}=\dot{\chi}_{t}=\lambda \sigma \theta l_{t} \chi_{t}, \forall \omega \in \Omega$. Therefore, one has

$$
g_{\chi_{\omega t}}=g_{\chi_{t}}=g_{\mathcal{K}_{t}}=\lambda \sigma \theta l_{t}, \forall \omega \in \Omega
$$

Using (1), (6), and (14), the final good production function (5), the wage (12), and the final good resource constraint $(7)$ can be rewritten respectively as

$$
Y_{t}=\alpha^{\frac{\alpha}{1-\alpha}} L_{t}^{Y} \mathcal{K}_{t}, w_{t}=(1-\alpha) \alpha^{\frac{\alpha}{1-\alpha}} \mathcal{K}_{t} \text { and } Y_{t}=L c_{t}+\alpha^{\frac{1}{1-\alpha}} L_{t}^{Y} \mathcal{K}_{t}
$$

Dividing both sides of the expression of the final good resource constraint given in (61) by $Y_{t}$, one gets $L c_{t} / Y_{t}=1-\alpha$. Log-differentiating with respect to time this expression as well as the final good production function given in (61), one gets

$$
g_{c_{t}}=g_{Y_{t}}=g_{L_{t}^{Y}}+g_{\mathcal{K}_{t}}
$$

From (16) and (61), one gets the following social value of one unit of knowledge $\chi_{h t}$ :

$$
V_{h t}=V_{t}=\frac{(1-\alpha) \alpha^{\frac{\alpha}{1-\alpha}} \gamma L}{\lambda \sigma \theta}, \forall h \in \Omega
$$

Using (14), (63), the marginal profitabilities of knowledge given in Lemma 3 can be rewritten as follows:

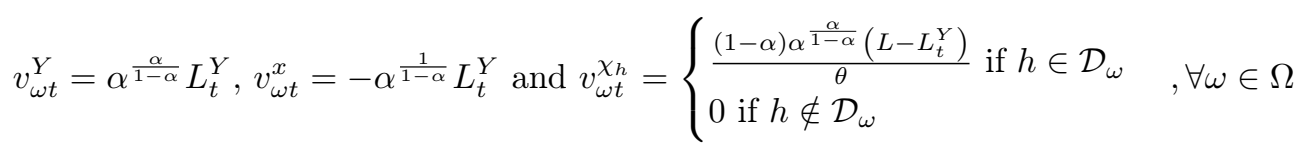

Accordingly, the instantaneous social value of one unit of knowledge $\chi_{\omega t}$ at date $t$ is

$$
v_{\omega t}=v_{\omega t}^{Y}+v_{\omega t}^{x}+\int_{\Omega} v_{\omega t}^{\chi_{h}} d h=(1-\alpha) \alpha^{\frac{\alpha}{1-\alpha}} L, \forall \omega \in \Omega
$$


From (63) and (64), one has $\dot{V}_{\omega t} / V_{\omega t}=0$ and $v_{\omega t} / V_{\omega t}=\lambda \sigma \theta / \gamma, \forall \omega \in \Omega$. Thus, from the arbitrage condition (59), one obtains the equilibrium interest rate:

$$
r_{t}=\frac{\lambda \sigma \theta}{\gamma}
$$

The partition of labor and the growth rates are characterized by (4), (58), (60), (62) and (65). From (58), (62) and (65), one gets $g_{c_{t}}=g_{Y_{t}}=g_{L_{t}^{Y}}+g_{\mathcal{K}_{t}}=\lambda \sigma \theta / \gamma-\rho$; and from (4) and (60), one gets $g_{\mathcal{K}_{t}}=g_{\chi_{t}}=\lambda \sigma \theta\left(1 / \gamma-L_{t}^{Y} / \gamma L\right)$. From these two expressions, one obtains $g_{L_{t}^{Y}}-\frac{\lambda \sigma \theta}{\gamma L} L_{t}^{Y}=-\rho$. Using the variable substitution $X_{t}=1 / L_{t}^{Y}$, one gets a first-order linear differential equation:

$$
g_{X_{t}}+\frac{\lambda \sigma \theta}{\gamma L} \frac{1}{X_{t}}=\rho \Leftrightarrow \dot{X}_{t}-\rho X_{t}=-\frac{\lambda \sigma \theta}{\gamma L}
$$

Its solution is $X_{t}=e^{\rho t}\left(X_{0}-\frac{\lambda \sigma \theta}{\rho \gamma L}\right)+\frac{\lambda \sigma \theta}{\rho \gamma L}$. Hence, one obtains

$$
L_{t}^{Y}=\frac{1}{e^{\rho t}\left(\frac{1}{L_{0}^{Y}}-\frac{\lambda \sigma \theta}{\rho \gamma L}\right)+\frac{\lambda \sigma \theta}{\rho \gamma L}}
$$

Using the transversality condition of the program of the representative household, it can be shown that $L_{t}^{Y}$ immediately jumps to its steady-state level $L^{Y^{s s}}=\rho \gamma L / \lambda \sigma \theta$. The transversality condition is only satisfied when $L_{t}^{Y}=L_{0}^{Y}, \forall t$. Hence, one has $L_{t}^{Y}=\rho \gamma L / \lambda \sigma \theta=L^{Y o}, \forall t$, and thus $g_{L_{t}^{Y}}^{o}=0$.

Thus, the partition of labor, the quantities of intermediate good, the quantities of knowledge and the growth rates are

$$
\begin{gathered}
L_{t}^{Y}=L^{Y o}=\frac{\rho \gamma L}{\lambda \sigma \theta} ; l_{\omega t}=l^{o}=\frac{1}{\gamma}-\frac{\rho}{\lambda \sigma \theta}, \forall \omega \in \Omega ; \\
x_{\omega t}=x^{o}=\alpha^{\frac{1}{1-\alpha}} \frac{\rho \gamma L}{\lambda \sigma \theta}, \forall \omega \in \Omega ; \\
\chi_{\omega t}=\chi_{t}^{o}=\frac{\mathcal{K}_{t}^{o}}{\gamma L}, \forall \omega \in \Omega ; \mathcal{K}_{t}^{o}=e^{g^{o} t} ; \\
\text { and } g_{c_{t}}=g_{Y_{t}}=g_{\mathcal{K}_{t}}=g_{\chi_{\omega t}}=g^{o}=\frac{\lambda \sigma \theta}{\gamma}-\rho, \forall \omega \in \Omega
\end{gathered}
$$

This proves that the quantities and growth rates computed in the Lindahl equilibrium are indeed those of the first-best social optimum. The system of prices is as follows.

- The prices of rival goods are $w_{t}^{o}=(1-\alpha) \alpha^{\frac{\alpha}{1-\alpha}} \mathcal{K}_{t}^{o} ; r_{t}^{o}=\frac{\lambda \sigma \theta}{\gamma} ; q_{\omega t}^{o}=q_{t}^{o}=\chi_{t}^{o}=\frac{\mathcal{K}_{t}^{o}}{\gamma L}, \forall \omega \in \Omega$.

- Regarding the pricing of knowledge, one has the following results.

- The personalized prices (Lindahl prices) of one unit of knowledge $\chi_{\omega t}$ for the final good sector, the intermediate sector $\omega$, and R\&D sector $h, h \in \Omega$, are $v_{\omega t}^{Y o}=\alpha^{\frac{\alpha}{1-\alpha}} \frac{\rho \gamma L}{\lambda \sigma \theta}, \forall \omega \in \Omega$; $v_{\omega t}^{x o}=-\alpha^{\frac{1}{1-\alpha}} \frac{\rho \gamma L}{\lambda \sigma \theta}, \forall \omega \in \Omega ;$ and $v_{\omega t}^{\chi_{h} o}=\left\{\begin{array}{l}\frac{(1-\alpha) \alpha^{\frac{\alpha}{1-\alpha}}}{\theta}\left(L-\frac{\rho \gamma L}{\lambda \sigma \theta}\right), \text { if } h \in \mathcal{D}_{\omega} \\ 0, \text { if } h \notin \mathcal{D}_{\omega}\end{array}, \forall \omega \in \Omega\right.$.

- The instantaneous income received by the producer of one unit of knowledge $\chi_{\omega t}$ is $v_{\omega t}^{o}=v_{\omega t}^{Y o}+v_{\omega t}^{x o}+v_{\omega t}^{R \& D o}=v^{o}=(1-\alpha) \alpha^{\frac{\alpha}{1-\alpha}} L, \forall \omega \in \Omega$, where $v_{\omega t}^{R \& D o}=\int_{\Omega} v_{\omega t}^{\chi_{h} o} d h=$ $(1-\alpha) \alpha^{\frac{\alpha}{1-\alpha}}\left(L-\frac{\rho \gamma L}{\lambda \sigma \theta}\right), \forall \omega \in \Omega$.

This proves Proposition 5. Finally, as seen in (11), an innovation consists in an increase in knowledge of $\Delta \chi_{\omega t}=\sigma \mathcal{P}_{\omega t}$ new units; moreover, from (63), the social value of one unit of knowledge $\chi_{\omega t}$ at date $t$ is $V_{\omega t}^{o}=\int_{t}^{\infty} v_{\omega t}^{o} e^{-\int_{t}^{s} r_{u} d u} d s=(1-\alpha) \alpha^{\frac{\alpha}{1-\alpha}} \gamma L / \lambda \sigma \theta$. The social value of an innovation in any sector $\omega, \omega \in \Omega$, is thus $\mathcal{V}_{\omega t}^{o}=\sigma \mathcal{P}_{\omega t}^{o} V_{\omega t}^{o}$, where $\mathcal{P}_{\omega t}^{o}=\theta \chi_{\omega t}^{o}=\theta \mathcal{K}_{t}^{o} / \gamma L$. Finally, one gets

$$
\mathcal{V}_{\omega t}^{o}=\frac{(1-\alpha) \alpha^{\frac{\alpha}{1-\alpha}}}{\lambda} \mathcal{K}_{t}^{o}, \forall \omega \in \Omega
$$

This proves Proposition 6 . 
We wish to thank Philippe Aghion, Jean-Luc Gaffard, Peter Howitt, Maurizio Iacopetta, Pietro Peretto, Gilles Saint-Paul, Bernard Salanié, John J. Seater, Francesco Vona, and the participants of the Workshop on Economic Growth (2011 and 2012) organized by NC State, OFCE and SKEMA Business School and of the EMAEE (2013). We also wish to thank very much two anonymous referees and the two Editors, Zakaria Babutsidze and Uwe Cantner, for their helpful comments and suggestions.

\section{Compliance with ethical standards}

The authors ensure that the researched work submitted is original, fully referenced, exclusive to Journal of Evolutionary Economics, not under consideration in any other journal, not published elsewhere, and that all authors are represented accurately.

Conflict of Interest: The authors declare that they have no conflict of interest.

\section{References}

[1] Acemoglu D (2009) Modern economic growth. Princeton University Press, Princeton NJ

[2] Acemoglu D, Akcigit U (2012) Intellectual property rights policy, competition and innovation. Journal of the European Economic Association 10(1):1-42

[3] Aghion P, Howitt P (1992) A model of growth through creative destruction. Econometrica $60(2): 323-351$

[4] Aghion P, Howitt P (1998) Endogenous growth theory. MIT Press, Cambridge MA

[5] Aghion P, Howitt P (2009) The economics of growth. MIT Press, Cambridge MA

[6] Alvarez-Pelaez MJ, Groth C (2005) Too little or too much R\&D? European Economic Review 49(2):437-456

[7] Barro R, Sala-i-Martin X (2003) Economic Growth, second edition. MIT Press, Cambridge MA

[8] Benassy JP (1998) Is there always too little research in endogenous growth with expanding product variety? European Economic Review 42(1):61-69

[9] Bessen J, Maskin E (2009) Sequential innovation, patents, and imitation. The RAND Journal of Economics 40(4):611-635

[10] Chantrel E, Grimaud A, Tournemaine F (2012) Pricing knowledge and funding research of new technology sectors in a growth model. Journal of Public Economic Theory 14(3):493-520

[11] Chari V, Hopenhayn H (1991) Vintage human capital, growth, and the diffusion of new technology. Journal of Political Economy 99(6):1142-1165

[12] Chu AC, Cozzi G, Galli S (2012) Does intellectual monopoly stimulate or stifle innovation? European Economic Review 56(4):727-746

[13] Cozzi G, Giordani PE, Zamparelli L (2007) The refoundation of the symmetric equilibrium in Schumpeterian growth models. Journal of Economic Theory 136(1):788-797

[14] Dasgupta P, Mäler K, Navaretti G, Siniscalco D (1996) On institutions that produce and disseminate knowledge. Mimeo

[15] Dinopoulos E, Sener F (2007) New directions in Schumpeterian growth theory. In: Hanusch H, Pyka A (eds) The elgar companion to neo-Schumpeterian economics, Edward Elgar, Cheltenham

[16] Dinopoulos E, Thompson P (1998) Schumpeterian growth without scale effects. Journal of Economic Growth 3(4):313-335

[17] Garner P (2010) A note on endogenous growth and scale effects. Economics Letters 106(2):98100

[18] Green JR, Scotchmer S (1995) On the division of profit in sequential innovation. The RAND Journal of Economics 26(1): 20-33 
[19] Griliches Z (1992) The search for R\&D spillovers. Scandinavian Journal of Economics 94(supplement):29-47

[20] Griliches Z (1995) R\&D and productivity: econometric results and measurement issues. In: Stoneman P (ed) Handbook of the economics of innovation and technical change, Blackwell Handbooks in Economics

[21] Grossman G, Helpman E (1991) Quality ladders in the theory of growth. Review of Economic Studies 58(1):43-61

[22] Ha J, Howitt P (2007) Accounting for trends in productivity and R\&D: a Schumpeterian critique of semi-endogenous growth theory. Journal of Money, Credit and Banking 39(4):733774

[23] Hall B (2004) Innovation and diffusion. In: Fagerberg J, Mowery DC, Nelson RR (eds) Handbook on innovation, Oxford University Press, Oxford

[24] Hall B, Mairesse J, Mohnen P (2010) Measuring the returns to R\&D. In Hall B, Rosenberg $\mathrm{N}$ (eds) Handbook of the economics of innovation, Elsevier

[25] Howitt P (1999) Steady endogenous growth with population and R\&D inputs growing. Journal of Political Economy 107(4):715-730

[26] Jones C (1995) R\&D-based models of economic growth. Journal of Political Economy $103(4): 759-784$

[27] Jones C (1999) Growth: with or without scale effects? American Economic Review Papers and Proceedings 89(2):139-144

[28] Jones C (2005) Growth and ideas. In: Aghion P, Durlauf S (eds) Handbook of Economic Growth, Elsevier Volume 1B, 1063-1111

[29] Jones C, Williams J (2000) Too much of a good thing? The economics of investment in R\&D. Journal of Economic Growth 5(1):65-85

[30] Kaizuka K (1965) Public goods and decentralization of production. Review of Economics and Statistics 47(1):118-120

[31] Kortum S (1997) Research, patenting, and technological change Econometrica 65(6):1389-1419

[32] Laincz C, Peretto P (2006) Scale effects in endogenous growth theory: an error of aggregation not specification. Journal of Economic Growth 11(3):263-288

[33] Li CW (2002) Growth and scale effects: the role of knowledge spillovers. Economics Letters 74:177-185

[34] Li CW (2003) Endogenous growth without scale effects: a comment. American Economic Review 93(3):1009-1017

[35] Manning R, Markusen JR, Mc Millan J (1985) Paying for public inputs. American Economic Review 75(1):235-238

[36] Mas-Colell A, Whinston M, Green J (1995) Microeconomic theory. Oxford University Press, New York NY

[37] Milleron JC (1972) Theory of value with public goods: a survey article. Journal of Economic Theory 5(3):419-477

[38] O'Donoghue T, Zweimüller J (2004) Patents in a model of endogenous growth. Journal of Economic Growth 9(1):81-123.

[39] Peretto P (1998) Technological change and population growth. Journal of Economic Growth $3(4): 283-311$

[40] Peretto P (1999) Cost reduction, entry, and the interdependence of market structure and economic growth. Journal of Monetary Economics 43(1):173-195 
[41] Peretto P (2007) Corporate taxes, growth and welfare in a Schumpeterian economy. Journal of Economic Theory 137(1):353-382

[42] Peretto P, Smulders S (2002) Technological distance, growth and scale Effects. Economic Journal 112(481):603-624

[43] Quah DT (1997) Increasingly weightless economy. Bank of England Quarterly Bulletin $37(1): 49-56$

[44] Quah DT (2001) The weightless economy in economic development. In: Pohjola M (ed) Information technology, productivity and economic growth, Oxford University Press, Oxford, 72-96

[45] Romer P (1990) Endogenous technological change. Journal of Political Economy 98(5):71-102

[46] Salop S (1979) Monopolistic competition with outside goods. Bell Journal of Economics 10(1):141-156

[47] Sener F (2008) R\&D policies, endogenous growth and scale effects. Journal of Economic Dynamics and Control 32(12):3895-3916

[48] Scotchmer S (1991) Standing on the shoulders of giants: cumulative research and the patent law. Journal of Economic Perspective 5(1):29-41

[49] Scotchmer S (2005) Innovation and incentives. MIT Press, Cambridge MA

[50] Segerstrom P (1998) Endogenous growth without scale effects. American Economic Review 88(5):1290-1310

[51] Segerstrom P (2000) The long-run growth effects of R\&D subsidies. Journal of Economic Growth 5(3):277-305

[52] Segerstrom P (2007) Intel Economics. International Economic Review 48(1):247-280

[53] Tirole J (1988) The theory of industrial organization. MIT Press, Cambridge MA

[54] Young A (1998) Growth without scale effects. Journal of Political Economy 106(1):41-63 